\title{
Synoptic Composites of Tornadic and Nontornadic Outbreaks
}

\author{
ANDREW E. MERCER \\ Northern Gulf Institute, Mississippi State University, Mississippi State, Mississippi \\ Chad M. Shafer And Charles A. Doswell III \\ Cooperative Institute of Mesoscale Meteorological Studies, Norman, Oklahoma \\ LANCE M. LESLIE AND MichAEL B. RichMAN \\ School of Meteorology, University of Oklahoma, Norman, Oklahoma
}

(Manuscript received and in final form 25 January 2012)

\begin{abstract}
Tornadic and nontornadic outbreaks occur within the United States and elsewhere around the world each year with devastating effect. However, few studies have considered the physical differences between these two outbreak types. To address this issue, synoptic-scale pattern composites of tornadic and nontornadic outbreaks are formulated over North America using a rotated principal component analysis (RPCA). A cluster analysis of the RPC loadings group similar outbreak events, and the resulting map types represent an idealized composite of the constituent cases in each cluster. These composites are used to initialize a Weather Research and Forecasting Model (WRF) simulation of each hypothetical composite outbreak type in an effort to determine the WRF's capability to distinguish the outbreak type each composite represents.

Synoptic-scale pattern analyses of the composites reveal strikingly different characteristics within each outbreak type, particularly in the wind fields. The tornado outbreak composites reveal a strong low- and midlevel cyclone over the eastern Rockies, which is likely responsible for the observed surface low pressure system in the plains. Composite soundings from the hypothetical outbreak centroids reveal significantly greater bulk shear and storm-relative environmental helicity values in the tornado outbreak environment, whereas instability fields are similar between the two outbreak types. The WRF simulations of the map types confirm results observed in the composite soundings.
\end{abstract}

\section{Introduction}

The relative severity of an outbreak of severe weather is strongly related to the capacity of the outbreak to produce tornadoes. As such, it is of interest to forecasters to understand the meteorological differences that result in the formation of a tornado outbreak (TO) and a primarily nontornadic outbreak (NTO). The Glossary of Meteorology (Glickman 2000) describes a TO as "multiple tornado occurrences within a single synopticscale system." Tornado outbreaks are relatively rare, occurring only 20-30 times per year in the United States (Schneider et al. 2004). No formal definition exists for

Corresponding author address: Andrew E. Mercer, Northern Gulf Institute, Mississippi State University, 108 Hilbun Hall, P.O. Box 5448, Mississippi State, MS 39760-5448.

E-mail: mercer@hpc.msstate.edu a NTO, although Doswell et al. (2006, hereafter D06) identify NTOs as severe weather outbreaks with six or fewer tornadoes. Typically, 50 or more NTOs occur in a single year, but NTOs are generally less threatening to life and property than TOs. One fundamental feature of both TOs and NTOs is their association with a single synoptic system; understanding the underlying synopticscale structure associated with these two outbreak types is critical in determining the unique meteorological properties of each. The goal of this study is to assess these differences quantitatively using synoptic-scale pattern composites of each outbreak type.

Early studies of individual outbreak types (Carr 1952; Pautz 1969; Galway 1975, 1977; Grazulis 1993, among others) provide a baseline for the work in D06, which, in turn, serves as a point of departure for the current study. D06 provides a ranking of TOs and NTOs using severe weather report occurrence data from the Storm 
TABLE 1. List of some major synoptic studies of different (top) tornado outbreaks and (bottom) nontornadic outbreaks and the associated important synoptic features of each.

\begin{tabular}{|c|c|c|}
\hline Tornado outbreak study & Notable synoptic precursors & Outbreaks considered \\
\hline Fujita et al. (1970) & $\begin{array}{l}\text { Synoptic low over Iowa, midlevel trough over the upper } \\
\text { Mississippi Valley, zonal flow elsewhere }\end{array}$ & 11 Apr 1965 \\
\hline Ferguson et al. (1987) & $\begin{array}{l}\text { Strong low over the Midwest and upper mid-Atlantic, } \\
\text { upper-level 500-mb trough over southern Manitoba }\end{array}$ & 31 May 1985 \\
\hline Corfidi et al. (2010) & $\begin{array}{l}\text { Surface low over the central plains, deep } 500-\mathrm{mb} \text { trough } \\
\text { over the eastern Rockies, collocated jet streak left exit } \\
\text { region near the low formation location }\end{array}$ & 4 Apr 1974 \\
\hline Roebber et al. (2002) & $\begin{array}{l}\text { Dynamic tropopause and potential vorticity analysis of the } \\
3 \text { May } 1999 \text { tornado outbreak }\end{array}$ & 3 May 1999 \\
\hline Agee et al. (1975) & $\begin{array}{l}\text { Synoptic low over Iowa, midlevel trough over the upper } \\
\text { Mississippi Valley, zonal flow elsewhere }\end{array}$ & 4 Apr 1974 \\
\hline Lee et al. (2006) & $\begin{array}{l}\text { Forming surface low over Iowa, 500-mb trough west of } \\
\text { the low formation, } 300-\mathrm{mb} \text { jet streak contributing to } \\
\text { rapid low deepening and increasing vertical shear }\end{array}$ & 19 Apr 1996 \\
\hline Nontornadic outbreak study & Notable synoptic precursors & Outbreaks considered \\
\hline Burke and Schultz (2004) & $\begin{array}{l}\text { 500-mb trough over the eastern Rockies, low pressure } \\
\text { centered near the Oklahoma-Texas Panhandle }\end{array}$ & 50 cold season bow echo events \\
\hline Metz and Bosart (2010) & $\begin{array}{l}\text { Lee trough and deepening low pressure system over } \\
\text { the Midwest, enhanced southwesterly flow toward } \\
\text { Great Lakes }\end{array}$ & 3-5 Jul 2003 \\
\hline Johns (1984) & $\begin{array}{l}\text { Weak shortwave trough embedded in synoptic ridge over } \\
\text { central and western United States; strongly deepened } \\
\text { midlevel trough over the east }\end{array}$ & Climatology of 163 nontornadic events \\
\hline Coniglio et al. (2004) & $\begin{array}{l}\text { Found three primary types of derecho-forming environ- } \\
\text { ments characterized by either a well-defined upstream } \\
\text { trough, ridge, or zonal flow }\end{array}$ & 270 derecho events from 1980-2001 \\
\hline Johns (1993) & $\begin{array}{l}\text { Dynamic pattern similar to traditional tornado outbreak, } \\
\text { though low-level jet is more parallel to mid- and upper- } \\
\text { level jet, noted that conditions are not consistent for } \\
\text { different bow echo events }\end{array}$ & Analyzed many derechos from 1970-89 \\
\hline
\end{tabular}

Prediction Center [see Schaefer and Edwards (1999) for a review of that database], based on multiple weighted parameters associated with each outbreak type. This ranking scheme was used to determine the top 50 events during 1970-2003 for each outbreak type (referred to hereafter as "major outbreaks") from which the composites were derived.

Compositing has been conducted in many severe weather studies (e.g., Beebe 1956; Lowe and McKay 1962; Lanicci and Warner 1991). Schaefer and Doswell (1984) utilized empirical orthogonal functions (EOFs; Wilks 2006) in the creation of synoptic map types for TOs, based on a small sample of 14 events. Their analysis revealed two main synoptic flow patterns of TOs, with a smaller third category for a single event. Jones et al. (2004) incorporated a rotated principal component analysis (RPCA) to analyze the mesoscale detection algorithm (MDA) on the Weather Surveillance Radar1988 Doppler (WSR-88D) radar system. Many regional tornado composite studies have been undertaken as well (Mook 1954; Hagemeyer 1997; Gaffin and Parker 2006; Wasula et al. 2007; Banacos and Ekster 2010, etc.), typically by forming composites via simple averaging, rather than RPCA techniques.

Additionally, many case studies have revealed similar synoptic conditions preceding the formation of each type of outbreak (see Table 1 for a partial list of references). These studies characterize synoptic conditions prior to the formation of a TO with three key features:

- Upper-level trough axis west of the location of the outbreak that contributes to deepening of a surface cyclone through synoptic-scale processes (e.g., using quasigeostrophic theory).

- Upper-level jet streak collocated with the center of rapid surface pressure falls to intensify a synoptic cyclone and increasing vertical shear in the troposphere.

- Subsequent formation of a deep surface cyclone that incorporates a plume of enhanced moisture to develop large buoyant instability in the warm sector.

Johns and Hirt (1987, hereafter JH87) provide a checklist for precursors to derecho development, one of the 
most common types of NTOs in their appendix A. Some of these precursors include (see Table 1 for additional references) the following:

- Relatively shallow upper-level trough west of the outbreak location (JH87 note that a $500-\mathrm{mb}$ wind direction of $240^{\circ}$ to $360^{\circ}$ is a good synoptic precursor of a derecho).

- Advancement of the trough toward the region of derecho formation (characterized by JH87 as 60-m height falls in $12 \mathrm{~h}$ prior to derecho initiation).

- Sufficient instability commonly associated with a moisture axis located in the warm sector of the surface cyclone that results from the approaching upper-level trough.

Note that the derecho is one of many types of NTOs, though many events considered herein are derecho events owing to their widespread severity.

The synoptic patterns for most TOs and NTOs contain similar elements (the typical 500-mb trough west of the outbreak location and subsequent surface low formation, the presence of a moisture axis in the warm sector, etc.), though several key features in TOs are absent from NTOs (e.g., the jet streak influence on low formation is not observed as commonly in the NTO formation environment, implying enhanced vertical shear in the TO environment). Although some synoptic precursors that differ between TOs and NTOs have been identified by considering individual case studies or relatively small samples, no systematic study has been carried out to assess the aforementioned differences quantitatively through compositing a relatively large sample of major outbreaks of each type, and this is the primary goal of the current work. By following a specific methodology, RPCA assembles events into clusters based on their spatial patterns and is superior to an averaging of all events, which removes information about individual event types without prescreening.

The primary goal of this work is not to define synopticscale features characteristic of a TO, but to identify the synoptic-scale differences between TOs and NTOs. Furthermore, these composites can improve physical understanding of the synoptic-scale characteristics of individual outbreaks. That is, since they are composites, it is anticipated that the fields represent the physical structures on the synoptic scale common to all the outbreaks in the cluster, rather than including small-scale variability unique to individual events. Our hypothesis is that by contrasting extreme events (i.e., the top 50 TOs and NTOs) we enhance the likelihood of revealing synoptic-scale differences between the outbreak types, aiding in their accurate classification as TOs or NTOs. Alternatively, if synoptic fields of these significant outbreak events are similar for both TOs and NTOs, further composite outbreak research would not be fruitful (the null hypothesis).

\section{Data and methods}

\section{a. Data}

The National Centers for Environmental PredictionNational Center for Atmospheric Research (NCEPNCAR) reanalysis dataset (Kalnay et al. 1996), a global dataset defined on a $2.5^{\circ}$ latitude-longitude grid with 17 vertical levels, was used for the development of the composites. The composites were formulated using an outbreak-relative approach, since the outbreak centers vary widely over the study domain and the associated synoptic features should be positioned relative to these centers to preserve their structure in the compositing process (e.g., Fig. 1). The domain selected for each event was centered on a subjective outbreak centroid (as described in Mercer et al. 2009, hereafter M09) and extended latitudinally by $17.5^{\circ} \mathrm{N} / \mathrm{S}$ and longitudinally by $40^{\circ} \mathrm{E} / \mathrm{W}$. Expansion of the domain to this extent ensures the inclusion of relevant climatological features present in the ocean basins that may be important for outbreaks in the United States, particularly at 2- and 3-day lead time. Additionally, any nested WRF simulations that include the entire United States must have portions of both ocean basins in place to alleviate boundary condition issues.

Five meteorological variables were used in the creation of the composites: geopotential height, relative humidity, temperature, and $u$ and $v$ wind components at the 17 vertical levels. These reanalysis variables, according to Kalnay et al. (1996), have high reliability and are derived primarily from observational data. The relative humidity data in the NCEP-NCAR reanalysis data do not exist above $300 \mathrm{hPa}$, and since moisture content at this height is thought to be small, these missing values were set to zero. As no other missing data exist in the reanalysis and the dataset has high reliability, dataset errors should have little impact on the results of the composites.

D06 identified TOs and NTOs by considering severe weather reports in separate 24 -h periods (1200 UTC on the nominal date to 1200 UTC the following day). Of the cases selected, the median event time was closest to 0000 UTC. For example, for the 3 May 1999 outbreak, the outbreak valid time was considered to be at 0000 UTC 4 May 1999. The NCEP-NCAR reanalysis data are available at 6-h intervals; hence, 13 grids for each case were obtained to allow for a 72-h lead time for the composites. 


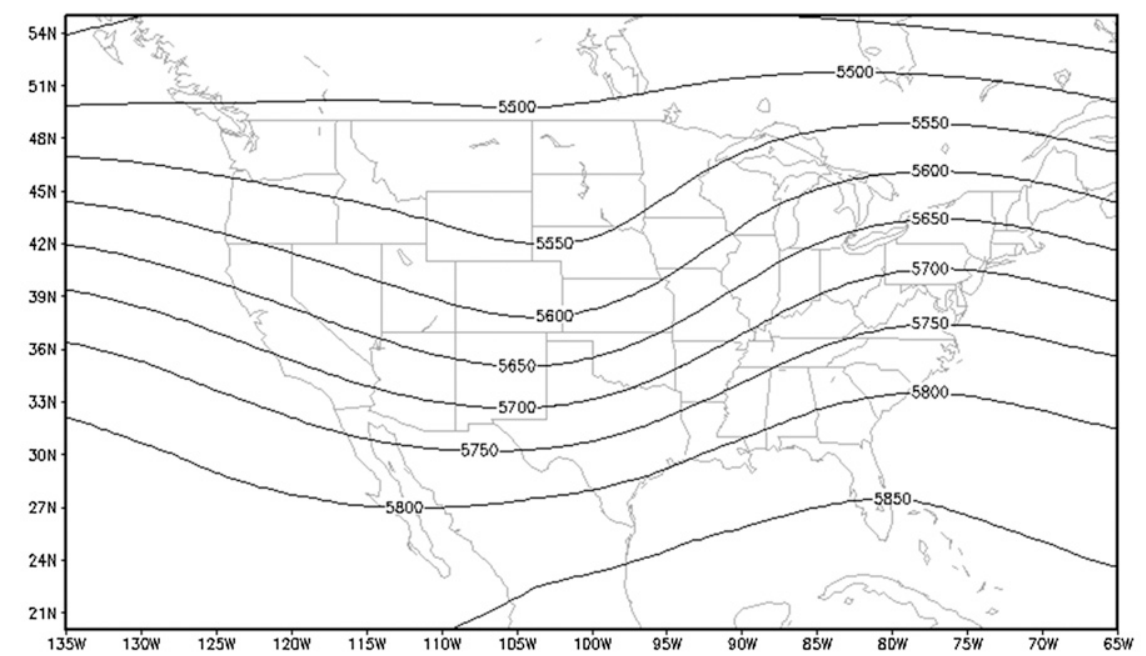

(a)

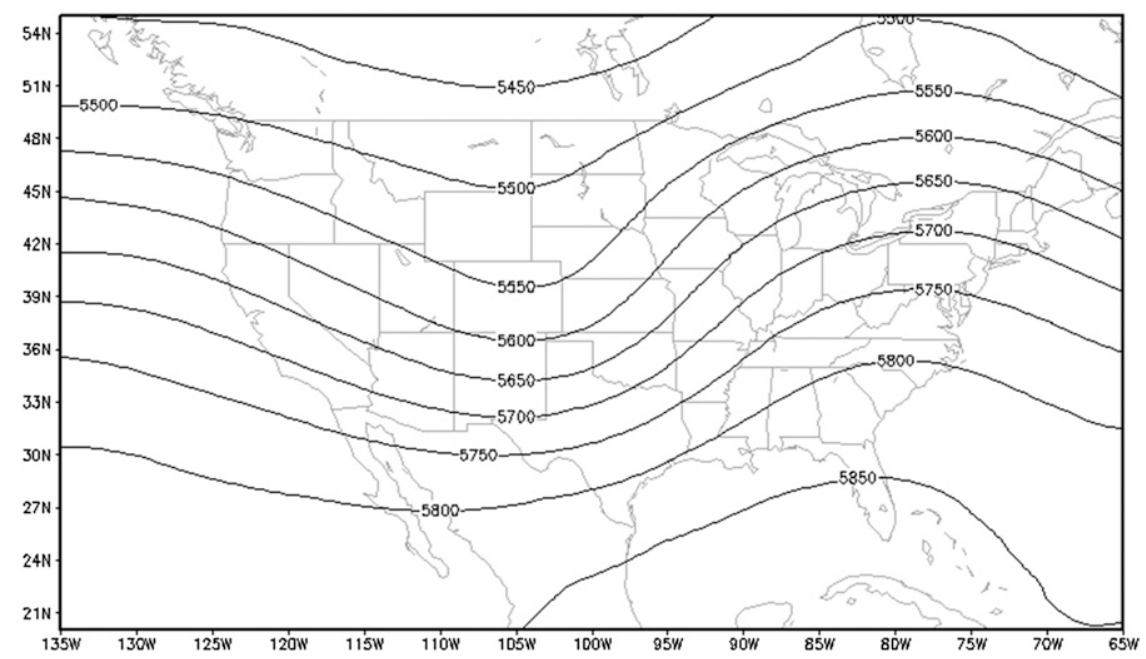

(b)

FIG. 1. Composite height map from averaging on (a) a fixed domain and (b) an outbreakrelative domain. Note the more amplified trough-ridge couplet over the central and eastern United States in the outbreak-relative domain.

\section{b. Composite method}

Several methods were considered for developing the composites. A common technique, simple unsupervised averaging, can produce a composite that fails to resemble the individual case events, since there is more than one type of variability in the composite pool. As a simple example, if an equal number of cases with northwest flow and with southwest flow are averaged, the result would be a purely westerly flow, which would not be an accurate composite for any of the individual cases. Supervised averaging can be a useful compositing technique but requires the meteorologist to visually inspect every event for consistency with the mean, which is a time-consuming task. A more elegant approach that captures properly the variability associated with each outbreak type, RPCA (i.e., Richman 1986), was selected for the formulation of the composites. Some modifications to the traditional RPCA methodology were required, owing to the nature of the specific problem being investigated, and are described below.

The PCA equation is given as

$$
\mathbf{Z}=\mathbf{F A}^{\mathrm{T}},
$$

where $\mathbf{Z}$ represents a standardized anomaly matrix of the input data, $\mathbf{F}$ represents a matrix of principal component (PC) scores (Wilks 2006), and A represents 
a matrix of PC loadings (Wilks 2006). The score matrix $\mathbf{F}$ is a transformation of $\mathbf{Z}$ such that the column vectors in $\mathbf{F}$ are uncorrelated. The loading matrix $\mathbf{A}$ is used to transform between the original data and the uncorrelated score data, and $\mathbf{A}$ represents a linear combination of the terms in $\mathbf{F}$ that can be used to reproduce $\mathbf{Z}$. Additionally, the columns of $\mathbf{A}$ are in order of decreasing variability explained of $\mathbf{Z}$.

To determine $\mathbf{F}$ and $\mathbf{A}$, the data in $\mathbf{Z}$ first were standardized. Typically, this involves removing the mean and dividing by the standard deviation of each "variable." For the present study, this method is problematic, since the 5 variables and 17 vertical levels have vastly different magnitudes (i.e., 300-mb height vs relative humidity). Instead, standardization through the calculation of standard anomalies was done by vertical level and variable within each column to ensure that by converting the data to statistical units, the magnitudes were similar for all grid points and that consistency is retained.

Following the initial data standardization, the correlation matrix $\mathbf{R}$ of $\mathbf{Z}$ is computed using

$$
\mathbf{R}=\frac{\mathbf{Z}^{\mathrm{T}} \mathbf{Z}}{n-1}
$$

Several issues arise in the computation of the correlation matrix. As the initial dataset consists of 52955 grid points for 50 events of each outbreak type, it is necessary to determine over which dimension of $\mathbf{Z}$ the correlations should be computed. The scientific question is, what dimension of the data matrix are we interested in probing for our specific research goals, the correlations between the rows (grid points) or the correlations between the columns (events)? Richman (1986) defines these two scenarios as a $T$ mode (correlations computed along the time dimension, which are the outbreaks in this study) and an $S$ mode (correlations computed along the gridpoint dimension). As it is the relationships between the cases that are of interest in this study, the $T$-mode analysis was selected, yielding a $50 \times 50$ event dimension $\mathbf{R}$ matrix for each outbreak type. Selection of $T$ mode had computational advantages as well, as it is computationally challenging to create and diagonalize a correlation matrix of dimension 52955 .

An additional concern is that grid points that are closer spatially tend to be more highly correlated than points spaced far apart. The NCEP-NCAR reanalysis data reside on a latitude-longitude grid, which has significant gridpoint convergence near the poles (Fig. 2a). Thus, the native reanalysis grid will influence the correlations artificially near the poles. Since the patterns produced by the RPCA reflect the variability in the correlation matrix, it is desirable to have the correlations

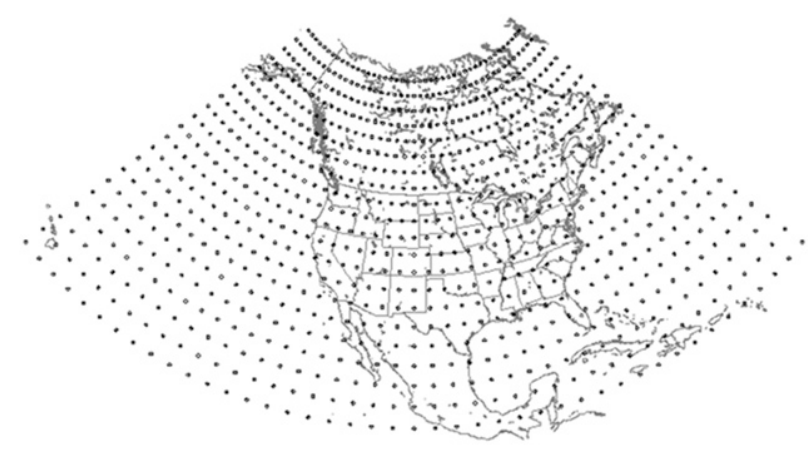

(a)

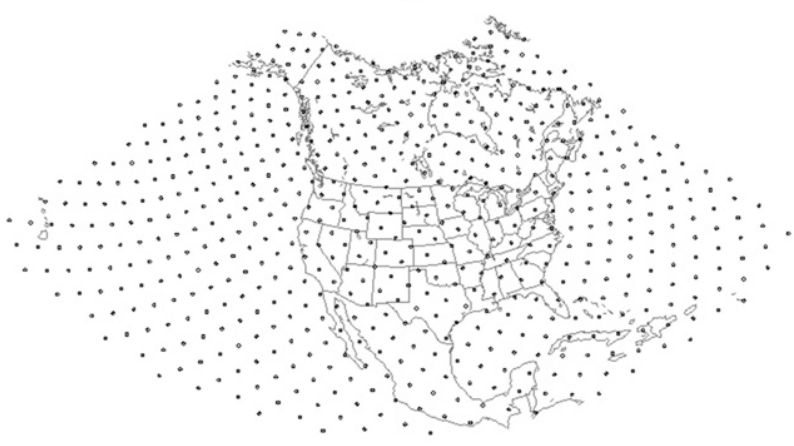

(b)

FIG. 2. (a) Composite domain grid and (b) the Fibonacci grid as defined by Swinbank and Purser (2006).

reflecting the spatial association of the variables without confounding that association by convergence of the grid points. To eliminate this issue, an equally spaced hemispheric grid is applied. Swinbank and Purser (2006) define a Fibonacci grid (Fig. 2b), which uses the Golden ratio $[\Phi=(1+\sqrt{5}) / 2]$ and a predetermined number of grid points $N$ to compute an equally spaced hemispheric grid. In the current study, $N=3000$ was selected to ensure similar grid spacing to the NCEP-NCAR reanalysis data and thereby retain the synoptic-scale grid spacing. The latitudes (i.e., 3) and longitudes (i.e., 4) of the Fibonacci grid are defined by

$$
\begin{aligned}
\sin \theta_{i} & =\frac{2 i}{2 N+1}, \\
\lambda_{i} & =2 \pi i \Phi^{-1} .
\end{aligned}
$$

The data grid is created by a one-pass Barnes' objective analysis (Barnes 1964) with a scale length of $1 \times 10^{5} \mathrm{~km}^{2}$, and the analysis root-mean-square error is less than $1 \%$ of the magnitude of the variables, which was deemed acceptable for the current study. A subset of the hemispheric domain, 625 grid points, was retained as part of the outbreak-relative compositing domain for the computation of $\mathbf{R}$. 
The correlation matrix $\mathbf{R}$ is diagonalized into an eigenvalue matrix $\mathbf{D}$ with associated an eigenvector matrix $\mathbf{V}$ given by

$$
\mathbf{R}=\mathbf{V D V}^{\mathrm{T}}
$$

Typically, an eigensolver (e.g., R; Bell Laboratories 2011) can be utilized to solve this equation, and the resulting eigenvector matrix defines a new coordinate system. Note that, by definition, eigenvectors point in directions of maximum variability within a dataset. This eigenvalue-variance relationship suggests that a small subset of the original eigenvalues associated with eigenvector matrix $\mathbf{V}$ describes most of the meaningful variability in $\mathbf{Z}$. To prevent fitting composites representing noise (low-variability eigenvalues), the matrix $\mathbf{V}$ must be truncated prior to the final computation of $\mathbf{F}$ to retain only the eigenvalues that include the most variability. However, if too few eigenvalues are retained, important signal information can be lost. The determination of the correct number of eigenvalues to retain for the present study is described below.

The truncated $\mathbf{V}$ and $\mathbf{D}$ matrices from this analysis are used to calculate the loading matrix $\mathbf{A}$ :

$$
\mathbf{A}=\mathbf{V D}^{1 / 2} .
$$

The largest eigenvalue is always associated with the first RPC and describes the greatest variability in the dataset. Subsequent eigenvalues decrease in magnitude monotonically to describe lower variability. However, the exact orientation of the associated eigenvectors may not truly point in the direction of the greatest localized variability owing to the constraint of orthogonality of the eigenvectors, but instead point between local variability maxima. To achieve the desired localization, the PC coordinate system is postprocessed with a linear transformation or "rotated" using a Varimax PC rotation (Richman 1986), providing a new rotated loading matrix $\mathbf{B}$ with the same dimensionality as $\mathbf{A}$ that accounts for the same total variance explained as in $\mathbf{A}$.

The formulation of $\mathbf{B}$ provides another essential component of compositing studies such as that provided herein. For unrotated PCA, a large percentage of the variability is often captured in the first few PC score vectors (PCs), and in the present study, $50 \%$ of the total variability is retained using the first unrotated $\mathrm{PC}$, with only $5 \%$ retained by the second PC. This suggests that retaining PC2 is unnecessary (and often is mistakenly truncated using traditional scree tests or North's test; North et al. 1982). After rotating the loadings, the same $55 \%$ of the variability described by the unrotated loadings is distributed as $30 \%$ in PC1 and $25 \%$ in PC2, and the resulting fields are more physically consistent with the observed events. A simple demonstration of this for TOs (Fig. 3) reveals that, after rotation, the PC maps have a different spatial structure, particularly noting PC2. However, important distinctions are observed between rotated PC1 and PC2 (Figs. 3c,d) as well, particularly the shortwave anomaly trough in the northwest quadrant of the domain in PC1, a feature observed in many case studies (see Table 1). This feature is absent in the unrotated maps (Figs. 3a,b) whereas an upstream shortwave trough has been shown in the literature to be a common occurrence prior to TO events (e.g., Table 1).

Finally, individual map types of each outbreak type are created using $\mathbf{B}$. The rotated PC loading matrix B represents the weights used to create a linear combination of the $\mathbf{F}$ matrix to most efficiently reproduce a percentage of the variance in $\mathbf{Z}$. That is, the rotated loadings represent the relationship between the 50 individual outbreaks for each type and F. Grouping rotated loadings with similar magnitudes will indicate which individual events most closely match columns of $\mathbf{F}$, thereby clustering outbreak events that have similar synoptic structures (e.g., Fig. 4). This clustering is based entirely on $\mathbf{B}$, so the direct computation of $\mathbf{F}$ was not undertaken in this study. Grouping was accomplished through a nonhierarchical $k$-means cluster analysis (Wilks 2006) of the PC loadings for each outbreak type. This approach is desirable, as RPC loadings alone often isolate localized significant features that are not representative of the full atmospheric profile (e.g., Richman and Mercer 2012). By combining these localized features through clustering, a full atmospheric snapshot for each outbreak type can be attained. Clusters were obtained from the individual event magnitudes of the PC loadings. However, a $k$-means cluster analysis requires prior knowledge of the number of composite map types for each outbreak type.

As acknowledged previously, the correct number of PCs to retain and the correct number of clusters to compute was unknown for this dataset. These decisions were based on the silhouette coefficient (Rousseeuw 1987). The silhouette coefficient is given by:

$$
\text { Silhouette }(\mathbf{a})=\frac{\operatorname{Separation}(\mathbf{a})-\operatorname{Cohesion}(\mathbf{a})}{\max [\operatorname{Separation}(\mathbf{a}), \operatorname{Cohesion}(\mathbf{a})]} .
$$

Here, separation represents a measure of the distance between the nearest members in different clusters, while cohesion represents the average distance from the center to the members of a cluster. It is optimal to maximize cluster separation and minimize cluster cohesion. By using this approach iteratively for several combinations of PCs retained and for numbers of clusters, it was found 


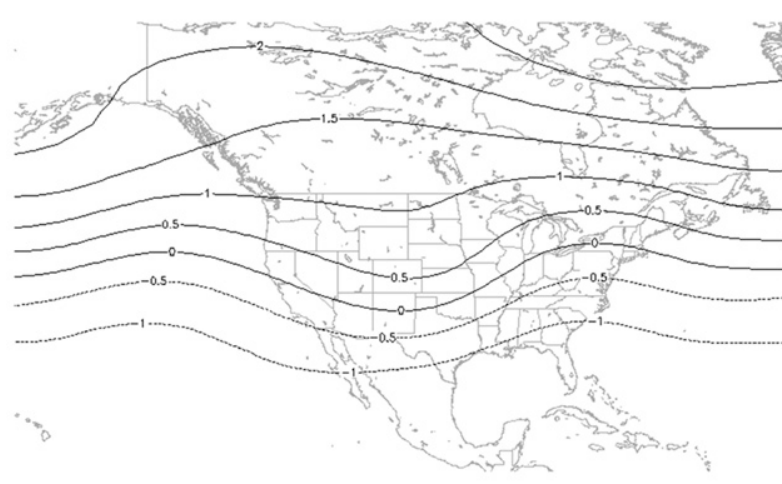

(a)

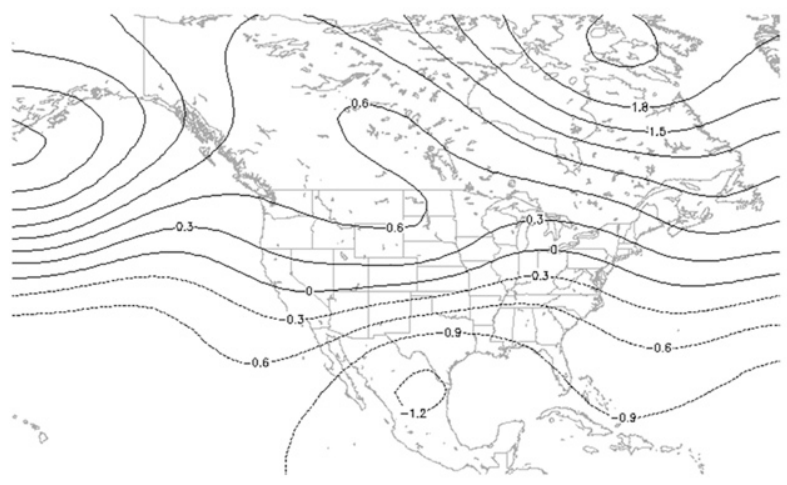

(c)

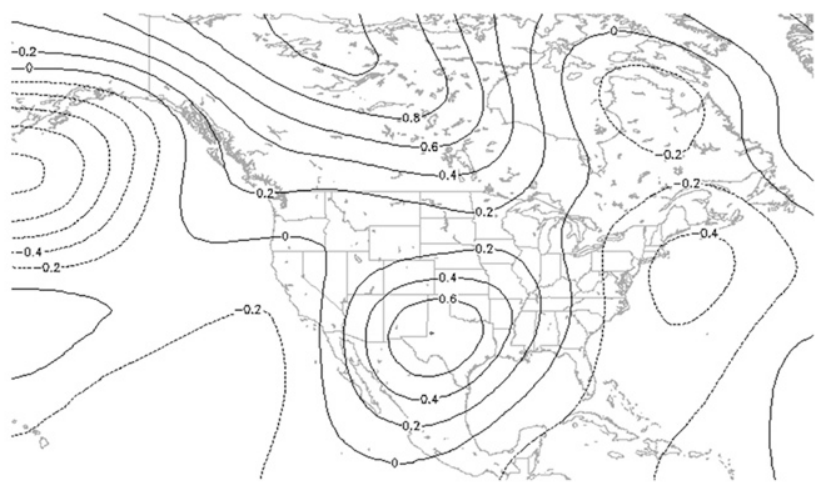

(b)

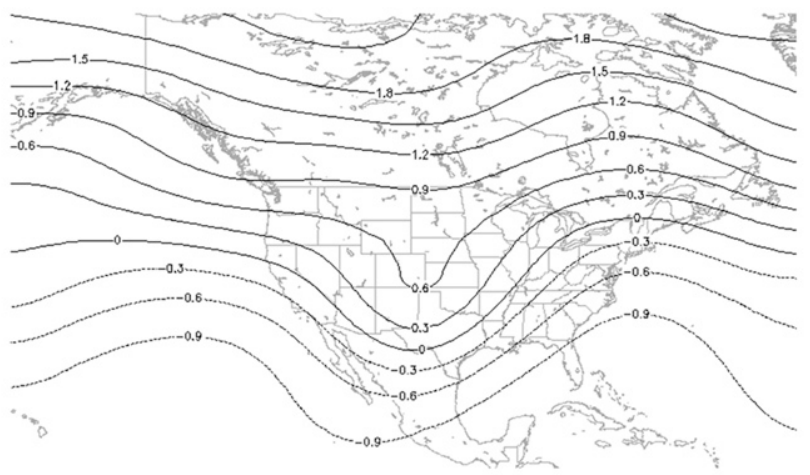

(d)

FIG. 3. Plots of (a),(b) unrotated PC1 and PC2 for TOs and (c),(d) Varimax rotated PC1 and PC2 for TOs.

that the correct number of PCs was 1 for both TOs and NTOs, and each outbreak type had optimal cluster cohesion and separation statistics with 6 clusters (total of 12 composites).

\section{c. WRF simulation and objective discrimination of outbreak type}

To test the representativeness of the composites, numerical weather prediction simulations of the composite fields [the Weather Research and Forecasting Model Advanced Research WRF core (WRF-ARW; Skamarock et al. 2008); in the present study, see Shafer et al. (2009, hereafter S09) for model parameterization description] were conducted to determine if the model was capable of discriminating outbreak type. The 12 map types for the two outbreak types were used as initial conditions for WRF. The resulting simulations were analyzed using the support vector machine (SVM; Cristianini and Shawe-Taylor 2000) algorithm presented in M09 for outbreak classification. The M09 algorithm was trained using the composite WRF simulations in an effort to determine the forecast usability of the composite maps. The M09 algorithm then was tested using WRF simulations of the original 100 outbreaks in M09 to determine the ability of the composites to distinguish outbreak type. In these analyses, an optimal combination of the original covariate set used in M09 was identified using a backward selection of predictors.

\section{Results and discussion}

\section{a. Interpretation of the synoptic pattern composites}

Synoptic-scale map types of both TOs and NTOs were compared to determine if unique meteorological features exist within the total TO and NTO case set. Note that the geographic location of each composite is not the region of highest outbreak activity, but instead is centered on the average location of all event centroids within each cluster. As such, the composites do not represent any individual event and so are geographically ambiguous. They are presented on a background map only to provide a sense of scale.

Whereas an orthogonal transformation was used in the rotation of the PC loadings, the resulting event clusters retained some correlation (Table 2) owing to the cluster analysis method. For the sake of brevity, three map types that have high correlations with other 


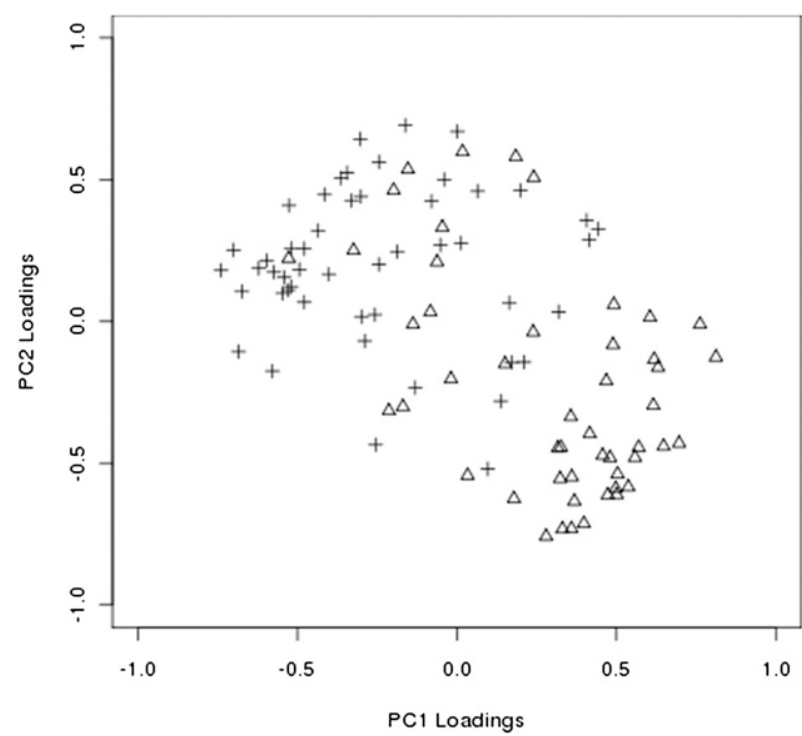

FIG. 4. Example scatterplot of the first two PC loading vectors of a combined PCA of TOs (crosses) and NTOs (triangles). The overlap between the two types demonstrates the difficulty of distinguishing between these two distinct types of outbreaks.

map types will be treated as representative of all map types (set boldfaced in Table 2), because the other map types appear similar. Further descriptions of these map types will follow the naming convention set forth in Table 2. Note that the cluster numbers are arbitrary; no ranking was assigned to the different map types.

Analysis of the 500-mb fields for the TO map types (Fig. 5) reveals that the expected trough-ridge pattern is consistent with previous tornado climatologies (e.g., Whiting and Bailey 1957; Fujita et al. 1970; Miller 1972; Doswell et al. 1993). However, within the three map types shown, the amplification of the trough-ridge pattern and associated relative vorticity is highly variable, with TO5 having the largest magnitude relative vorticity and a second vorticity maximum east of the primary troughridge pattern. These vorticity patterns suggest strong synoptic-scale ascent associated with quasigeostrophic (QG) differential vorticity advection and cyclogenesis, a result supported by the mean sea level pressure fields (not shown). The NTO patterns at $500 \mathrm{mb}$ (Fig. 6) are considerably different from the TO map types, as the patterns are considerably more zonal, especially the spring NTO pattern (NTO4; Fig. 6b). This seasonality has been characterized in previous work (Shafer et al. 2010) and is important in the current study as well, given that the synoptic environments governing summer and spring midlatitude conditions are considerably different (Hsu and Wallace 1976; S09). The zonal pattern in NTO2 is an indication of how highly variable the constituent members are for that cluster, suggesting that many
TABLE 2. Correlation matrices for the (top) TO map types and (bottom) NTO map types. The three boldfaced names for each type were the most representative maps, having higher correlations with the other three maps.

\begin{tabular}{lrrrrrr}
\hline \hline & TO1 & TO2 & TO3 & TO4 & TO5 & TO6 \\
\hline TO1 & 1.00 & -0.54 & 0.45 & -0.54 & -0.67 & 0.10 \\
TO2 & -0.54 & 1.00 & -0.53 & 0.01 & 0.40 & -0.39 \\
TO3 & 0.45 & -0.53 & 1.00 & -0.24 & -0.56 & -0.08 \\
TO4 & -0.54 & 0.01 & -0.24 & 1.00 & 0.11 & -0.01 \\
TO5 & -0.67 & 0.40 & -0.56 & 0.11 & 1.00 & -0.41 \\
TO6 & 0.10 & -0.39 & -0.08 & -0.01 & -0.41 & 1.00 \\
& NTO1 & NTO2 & NTO3 & NTO4 & NTO5 & NTO6 \\
\hline NTO1 & 1.00 & -0.50 & -0.40 & 0.32 & -0.12 & -0.44 \\
NTO2 & -0.50 & 1.00 & 0.45 & -0.62 & -0.18 & 0.04 \\
NTO3 & -0.40 & 0.45 & 1.00 & -0.62 & -0.15 & 0.08 \\
NTO4 & 0.32 & -0.62 & -0.62 & 1.00 & -0.25 & -0.41 \\
NTO5 & -0.12 & -0.18 & -0.15 & -0.25 & 1.00 & 0.00 \\
NTO6 & -0.44 & 0.04 & 0.08 & -0.41 & 0.00 & 1.00 \\
\hline
\end{tabular}

different meteorological conditions may be responsible for the representative spring NTO. Relative vorticity magnitudes are considerably weaker for the NTO map types as well, suggesting that any synoptic-scale ascent due to QG differential vorticity advection associated with NTOs is considerably weaker.

At $850 \mathrm{mb}$, deep low-level troughs are revealed in all three TO map types (Fig. 7). Additionally, warm, moist air is coincident with each approaching trough, combining with steep lapse rates (not shown) to produce buoyant instability for the TO as well as rapid synoptic-scale vertical ascent ahead of the propagating storm system due to QG warm air advection (not shown). Similar features exist in the NTO map types (Fig. 8), but are somewhat less amplified. However, visual inspection of the thermodynamic differences of the TO and NTO composites reveals few differences. One important difference can be seen in the geopotential height trough tilts; each tilt is accounted for by a TO composite [i.e., no tilt (TO1), positive tilt (TO5), and negative tilt (TO8)]. Generally speaking, the troughs associated with the NTOs all have a positive tilt that is far less amplified. The amplification of these tilts in the TO events suggests an increase in storm-relative environmental helicity (SREH) and vertical bulk shear in the TOs, as in previous work (e.g., M09; S09; Shafer et al. 2010).

To analyze vertical structure of the TOs and NTOs, a composite sounding of TO1 (Fig. 9) is compared with NTO2 (Fig. 10) at the time of outbreak initiation, since these are both late-spring composites. Both soundings (as well as the other 10 soundings) show no CAPE available for outbreak initiation. This is a result of the compositing methodology, since averaging the relative 


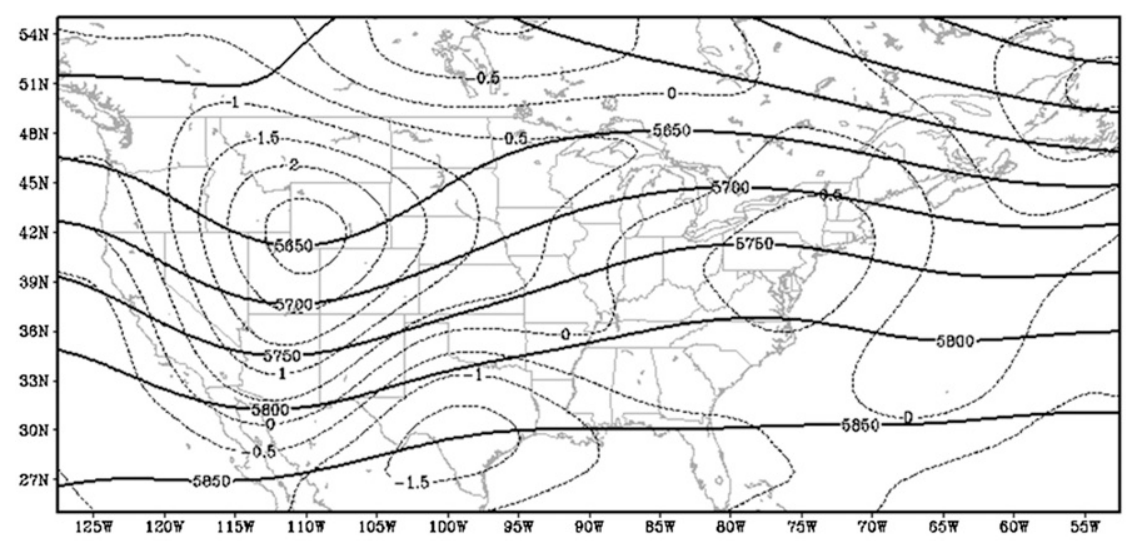

(a)

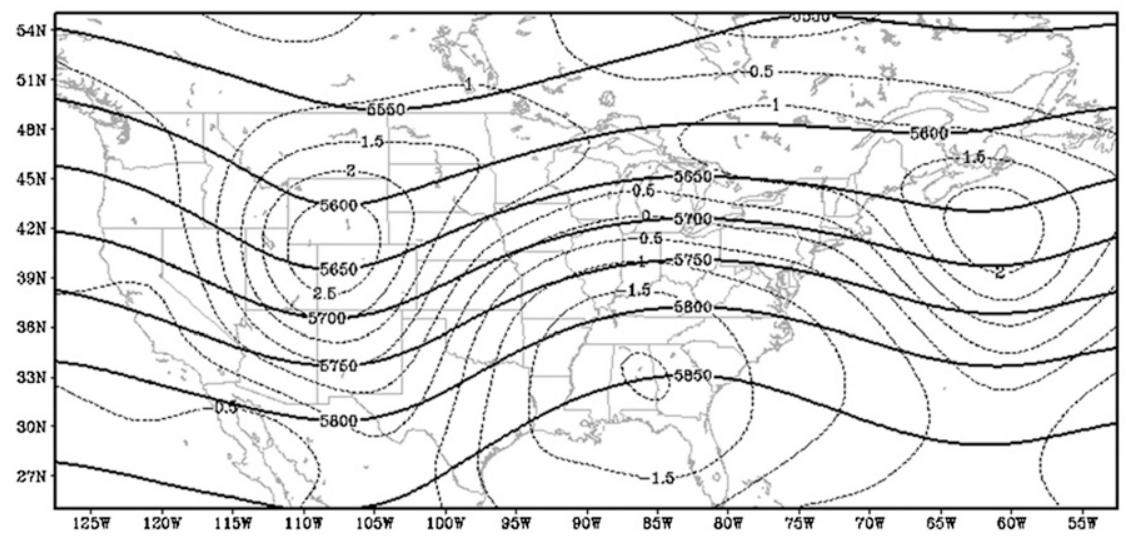

(b)

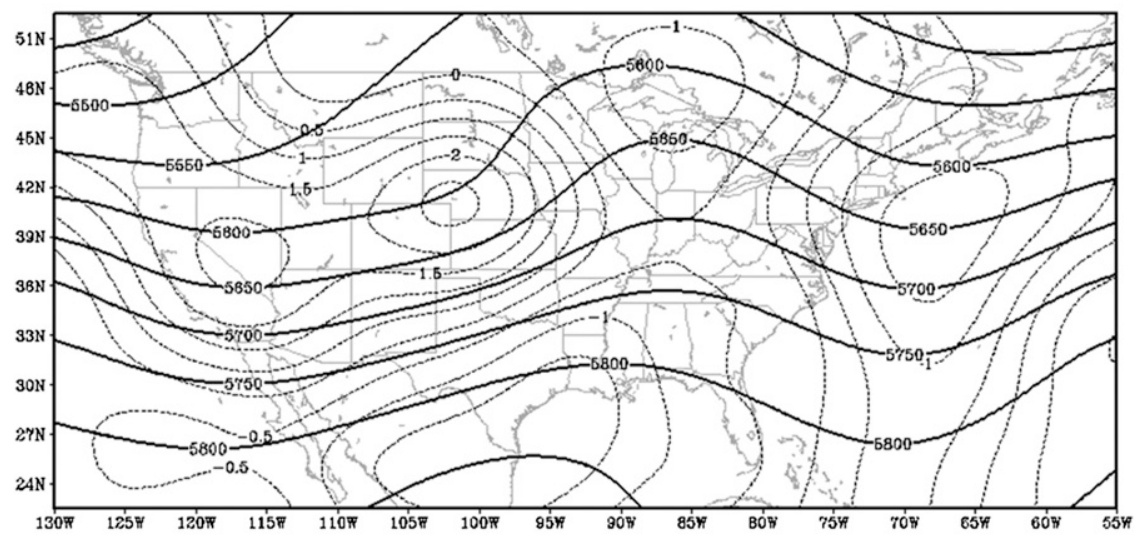

(c)

FIG. 5. 500-mb heights (solid contours) and relative vorticity $\left(10^{-5} \mathrm{~s}^{-1}\right.$, dashed lines) for TO clusters (a) 1 , (b) 5 , and (c) 8 at $24 \mathrm{~h}$ prior to outbreak initiation. The eventual outbreak will occur in the center of each domain, as defined previously.

humidity values of numerous cases reduced the overall moisture content of the composites such that CAPE calculations were zero. However, as shown in M09 and S09, CAPE is a poor discriminator of outbreak type, and WRF simulations (section $3 \mathrm{c}$ below) revealed highly variable CAPE values (on the order of 100-2000 J kg-1). The primary distinction between the composite TO and NTO soundings is the vertical wind structure. Considerably greater veering of the wind profile is observed in the TO profile, as well as greater vertical speed shear, 


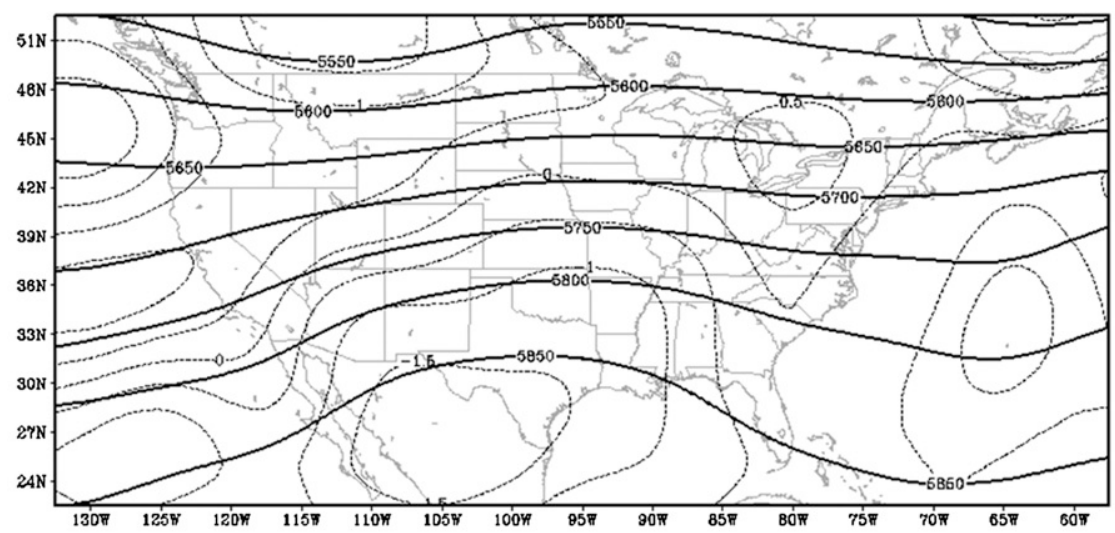

(a)

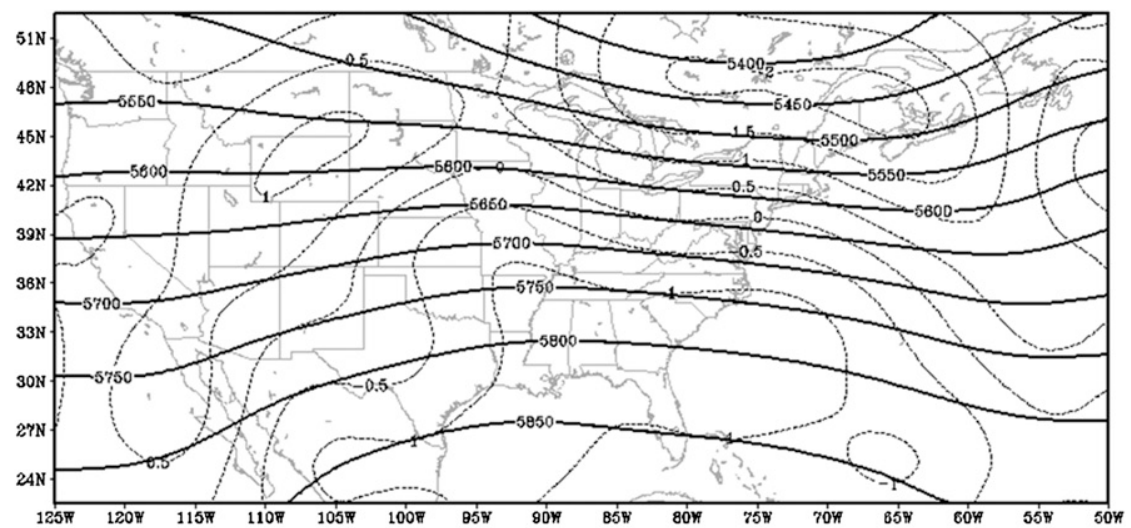

(b)

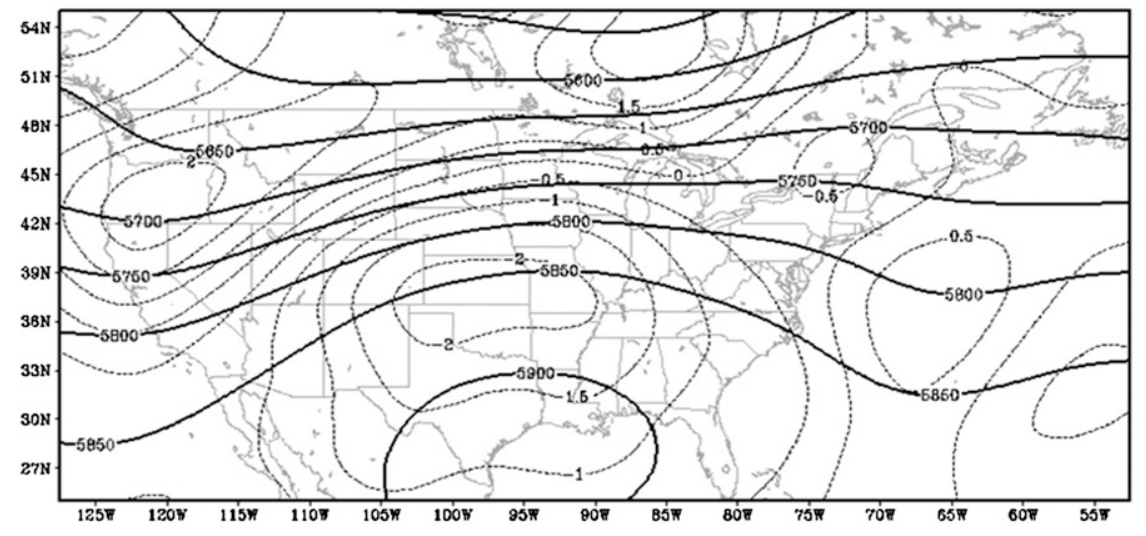

(c)

FIG. 6. 500-mb heights (solid contours) and relative vorticity $\left(10^{-5} \mathrm{~s}^{-1}\right.$, dashed lines) for NTO clusters (a) 1 , (b) 4 , and (c) 5 at 24 h prior to outbreak initiation. The eventual outbreak will occur in the center of each domain, as defined previously. NTO1 and NTO5 are summertime patterns, while NTO4 is a spring pattern.

supporting the larger helicity values in the TO1 composite sounding. Note that the smaller magnitudes of SREH $\left(109 \mathrm{~m}^{2} \mathrm{~s}^{-2}\right)$ seem low for a tornado outbreak, but have been reduced by the averaging methods employed (as was the case with the calculation for CAPE). The relatively large differences in the vertical wind profiles between the composites allow for easy identification of the outbreak type. 


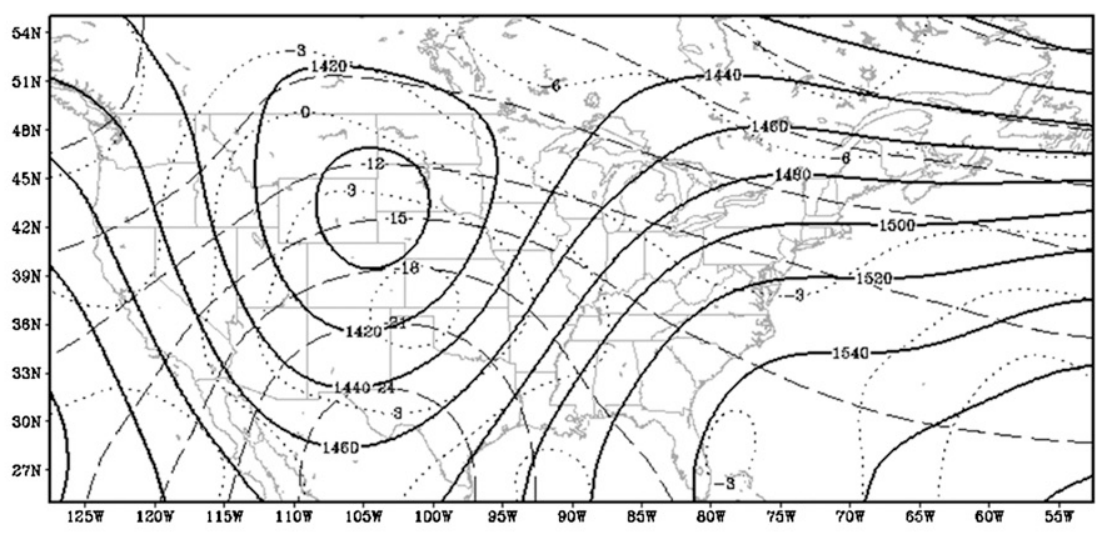

(a)

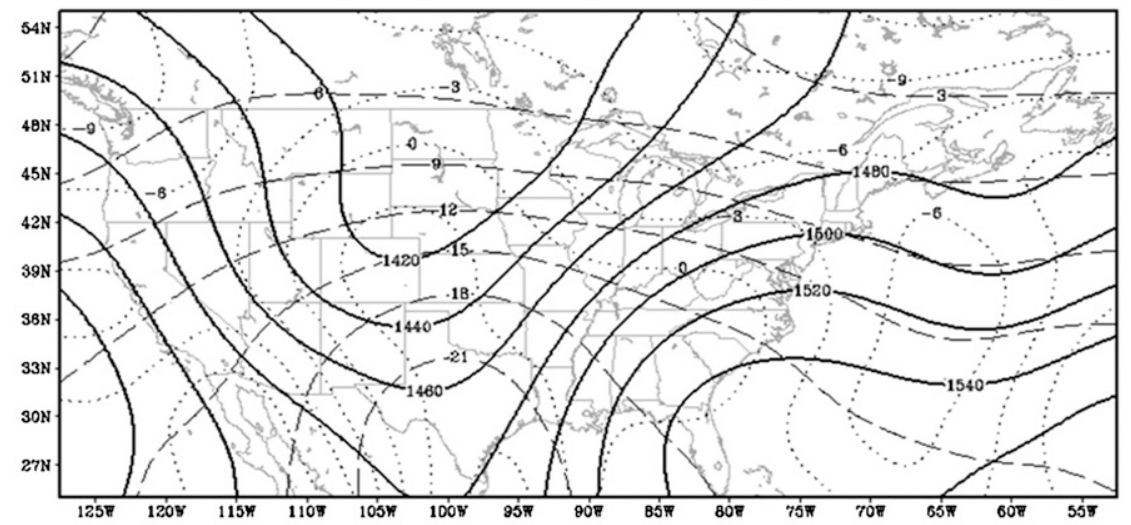

(b)

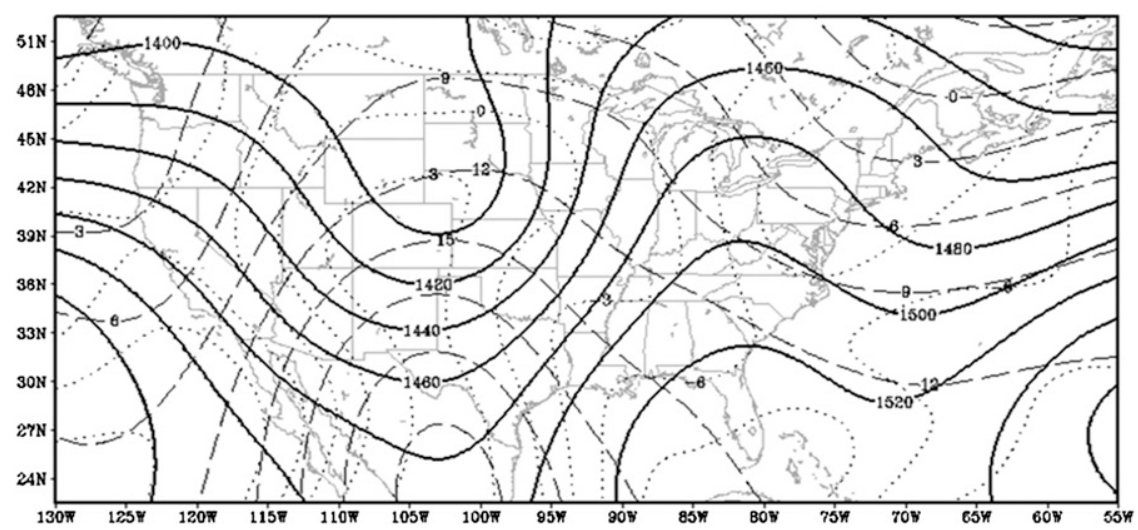

(c)

FIG. 7. As in Fig. 5, but for 850-mb heights (solid contours), temperature ( ${ }^{\circ} \mathrm{C}$, dashed lines), and dewpoint $\left({ }^{\circ} \mathrm{C}\right.$, dotted lines).

\section{b. Comparison to actual events}

To help validate the results, randomly selected outbreak events from TO1 (27 May 1973) and NTO4 (29 April 1981) are compared to their associated composite maps. The same 500- and 850-mb features of each event are provided directly from the NCEP-NCAR reanalysis to compare with the composites (Figs. 11-13).

The TO sample event (Figs. 11a,c) contains a collocated thermal and moisture maximum with the low-level trough pattern located over the eastern Great Basin and western plains during the actual event (Fig. 11c). The 


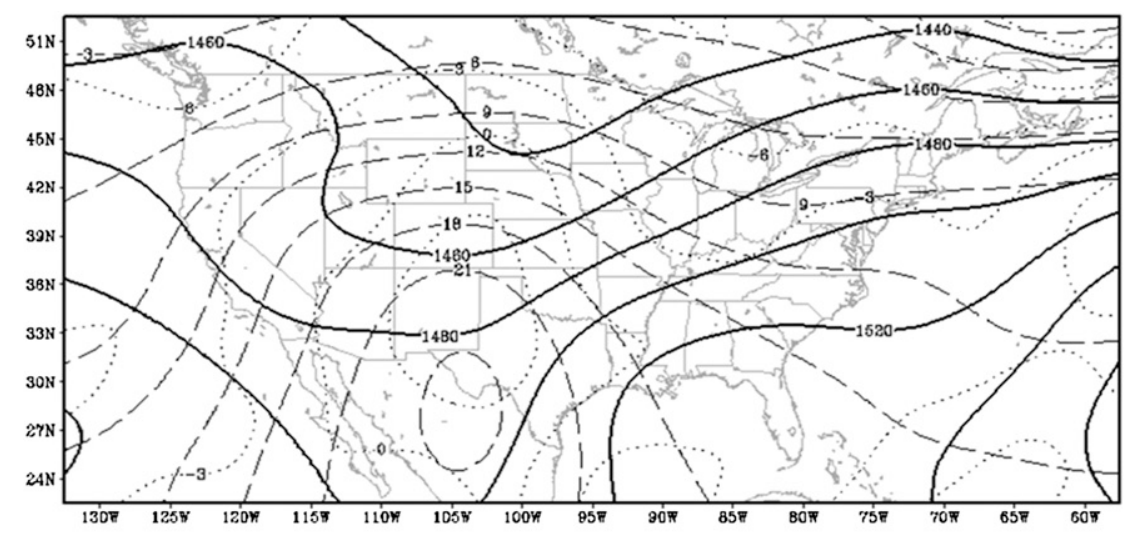

(a)

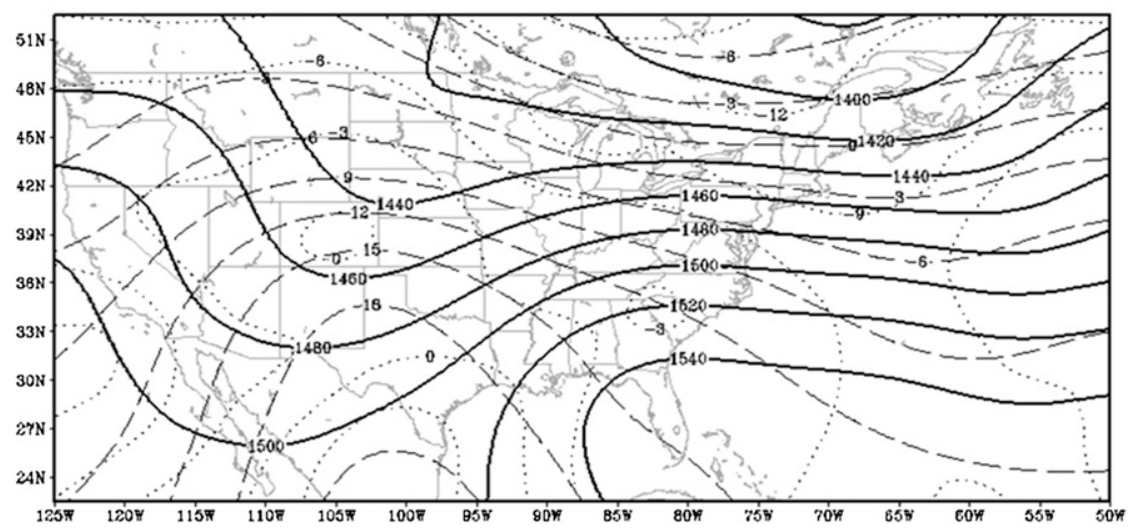

(b)

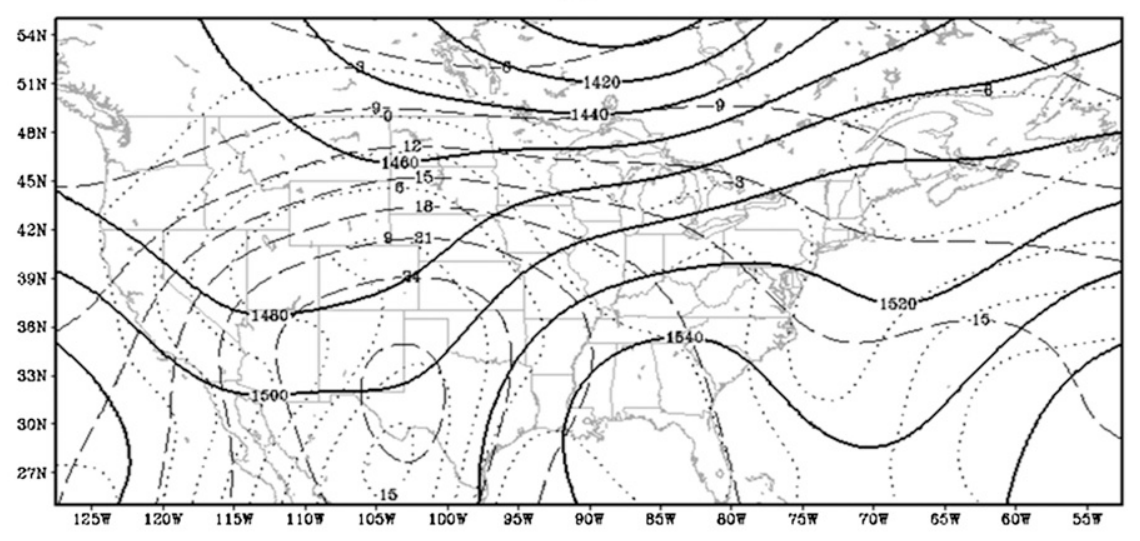

(c)

FIG. 8. As in Fig. 6, but for 850-mb heights (solid contours), temperature $\left({ }^{\circ} \mathrm{C}\right.$, dashed lines), and dewpoint $\left({ }^{\circ} \mathrm{C}\right.$, dotted lines).

averaging removes some of the variability present in the 500-mb sample TO field (Fig. 11a), as a strongly negatively tilted trough exists in the region of the eventual outbreak for this event. Relative vorticity values in the base of the trough are strong $\left(\sim 1 \times 10^{-4} \mathrm{~s}^{-1}\right)$.
The example NTO event (Figs. 11b,d) has few similarities to the NTO2 composite at $500 \mathrm{mb}$, demonstrating the high variability associated with spring NTO events. Some weak troughing of the height fields is present in the southwest corner of NTO4, showing the impact of this 
$\mathrm{mb}$
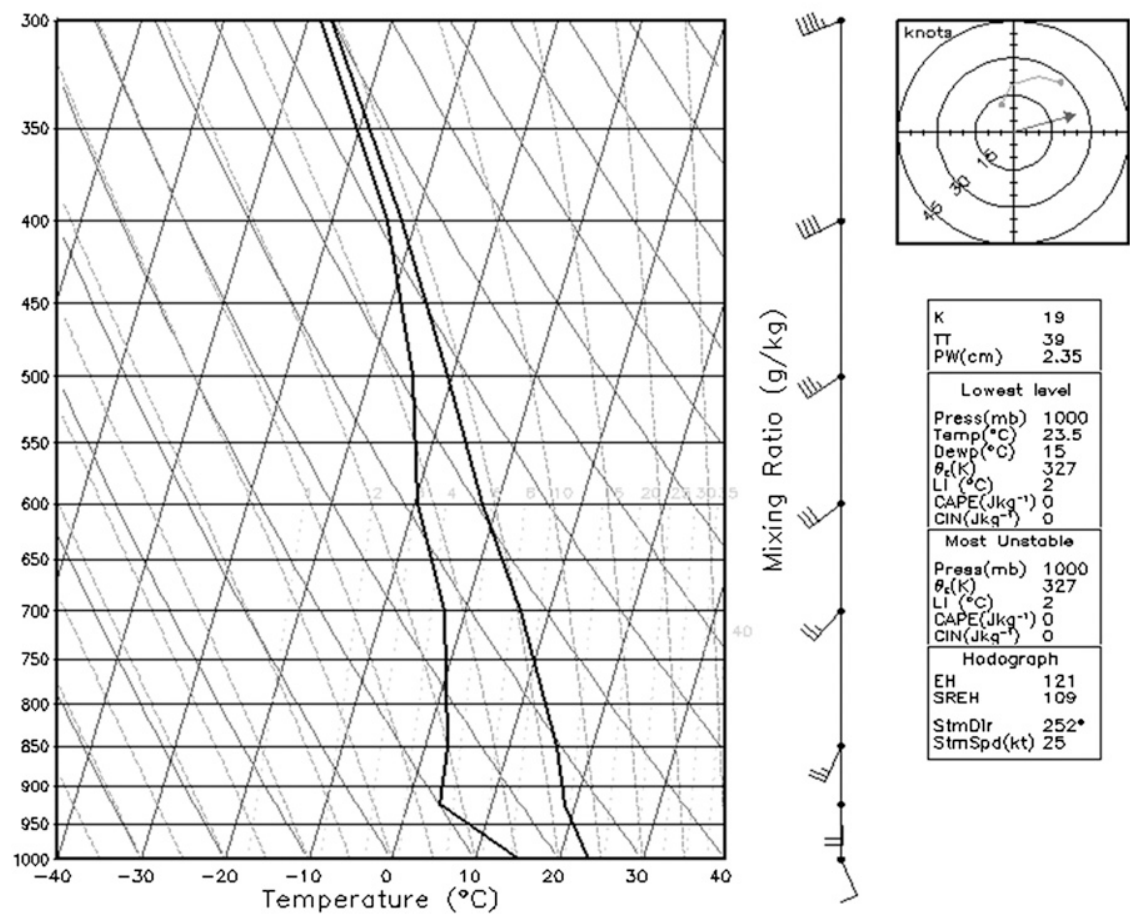

FIG. 9. Sounding of TO1, centered on the center of the domain at the outbreak valid time.

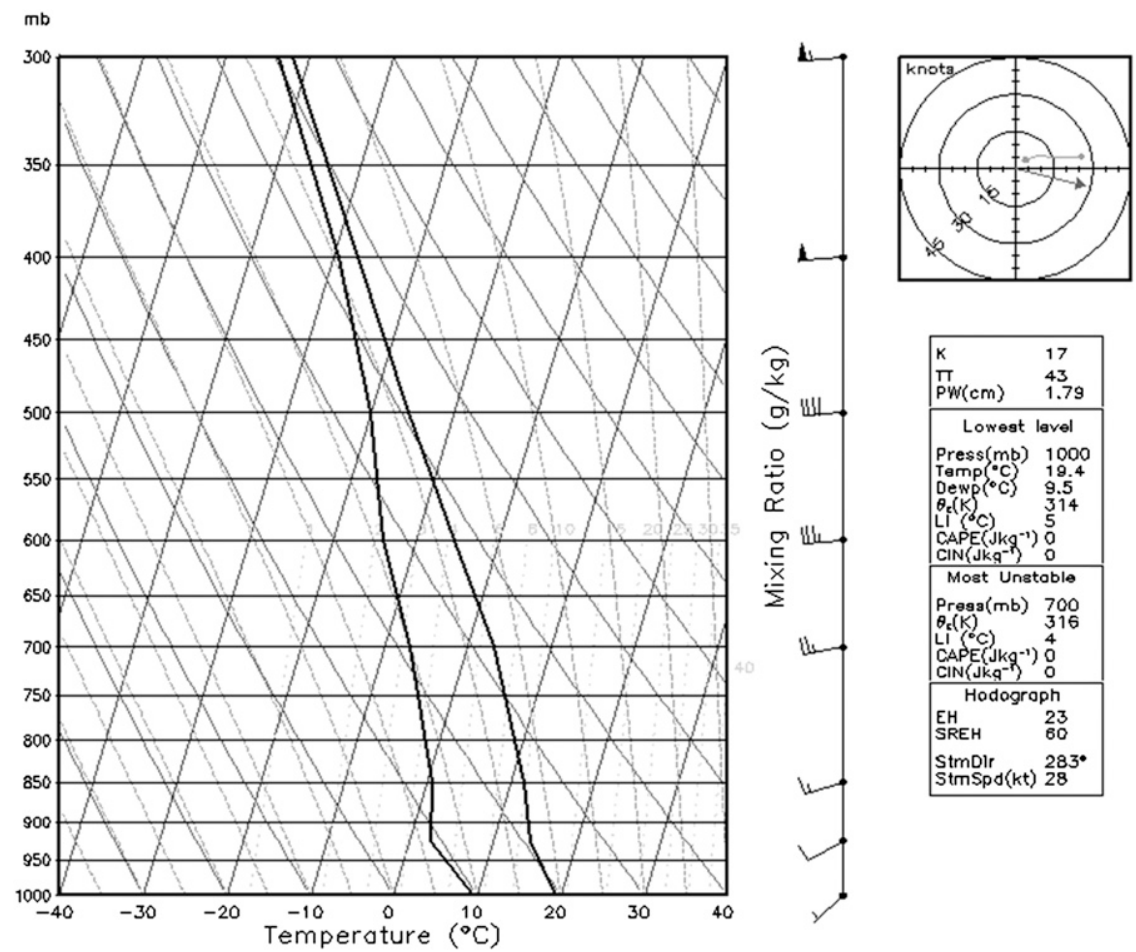

FIG. 10. Sounding of NTO4, centered on the center of the domain at the outbreak valid time. 


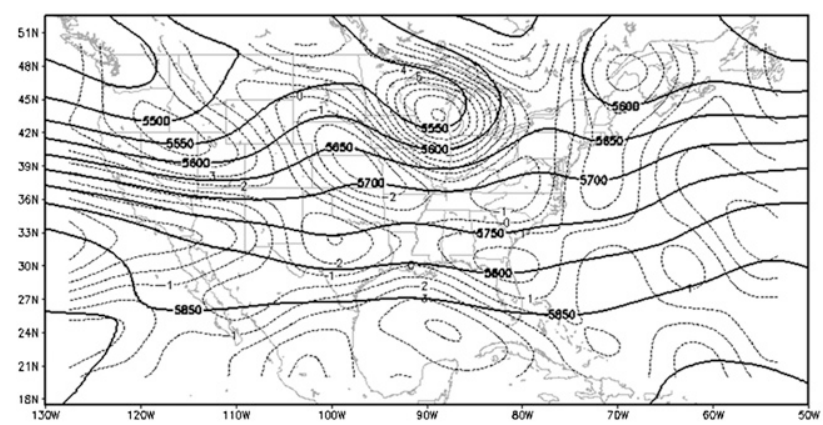

(a)

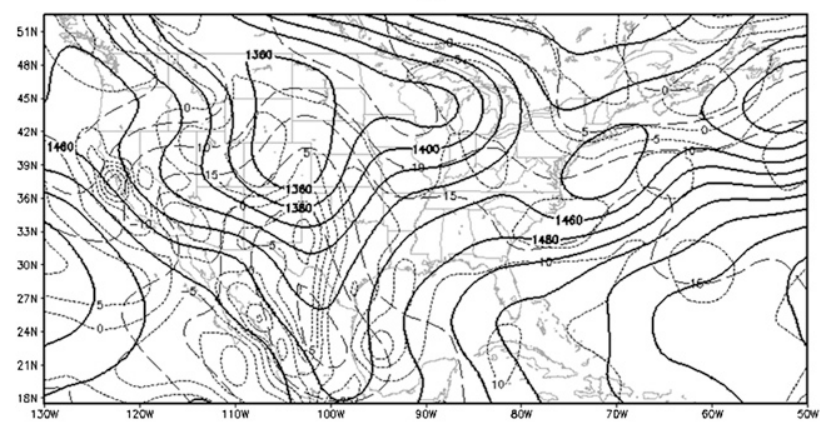

(c)

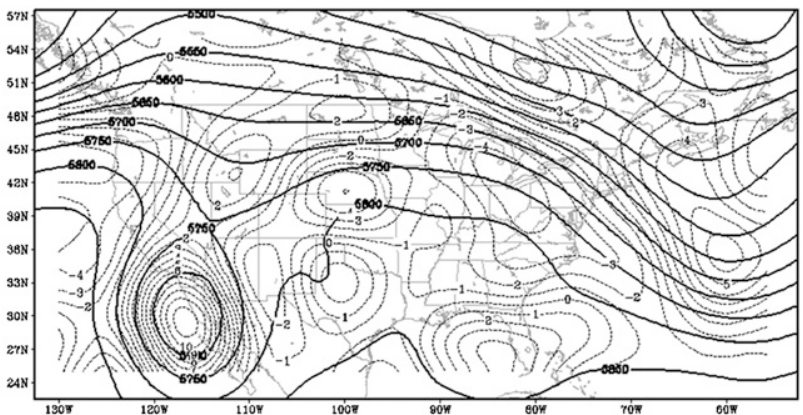

(b)

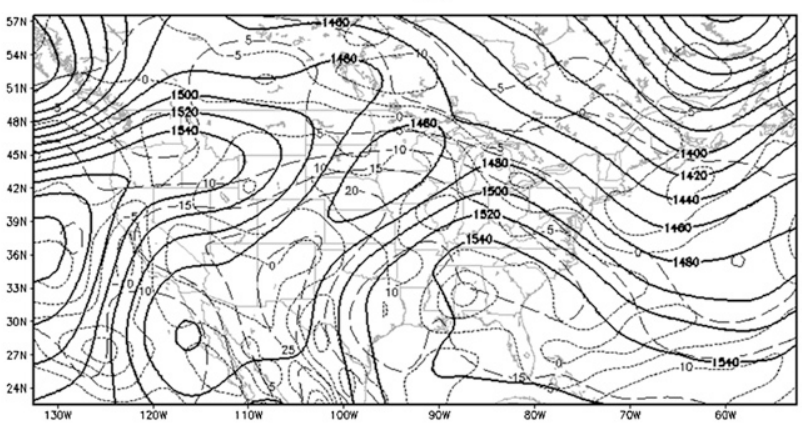

(d)

FIG. 11. Sample (a),(c) TO and (b),(d) NTO events to compare with the composites. The TO event is valid on 27 May 1973 and is a member of TO1, while the NTO event is valid for 29 Apr 1981 and is a member of NTO4. (a),(b) 500-mb heights (solid lines) and vorticity $\left(10^{-5} \mathrm{~s}^{-1}\right.$, dashed lines). (c),(d) 850-mb heights (solid lines), temperature $\left({ }^{\circ} \mathrm{C}\right.$, dashed lines), and dewpoint $\left({ }^{\circ} \mathrm{C}\right.$, dotted lines).

constituent event, but it is far too small to say the height fields match. The presence of the strong midlevel ridge in the NTO4 plot exists in the associated NTO sample plot as well and is a distinguishing feature from the TO1 example. A deep trough at $850 \mathrm{mb}$ exists in the sample event (Fig. 11d) and is roughly collocated with the composite trough. Additionally, the thermal maximum slightly downstream of the trough is present in both fields.

The soundings valid at the time of the 27 May 1973 event (Fig. 12) and the 29 April 1981 event (Fig. 13) reveal similar thermodynamic structure (1000-2000 CAPE) and vastly different vertical wind structure. Whereas the SREH values associated with the TO are lower than commonly observed for a TO, the veering of the wind profile with height and increase in vertical wind speed suggest conditions more commonly observed with TOs. The NTO sample event (Fig. 13) shows slight backing of the winds up to $700 \mathrm{mb}$ and positive vertical wind shear. As a result of this backing, SREH values are essentially zero, suggesting conditions are not conducive for tornado formation. These features are consistent with the TO and NTO composite soundings. Overall, these results suggest that the vertical wind patterns of each outbreak type are the best distinguishing characteristic.

\section{c. Map-type simulations}

To quantify the success of the composites at representing a given outbreak type, WRF simulations of each composite field and mean field were performed. The outbreak type each simulation was predicting was determined using the support vector machine algorithm and methodology developed in M09.

\section{1) AnAlysis OF WRF OUTPUT FIELDS}

The WRF was initialized with each composite to determine its ability at distinguishing outbreak types of the composites. Each map type was used as initial conditions to a WRF simulation centered on the composite average centroid. Two of the TO simulations (TO1 and TO5) and of the NTO simulations (NTO2 and NTO4) are provided for analysis. Relevant wind predictors based on results from M09 (0-6-km bulk shear in Fig. 14 and $0-1-\mathrm{km}$ SREH in Fig. 15) are provided to assess differences in the simulations of the composite outbreaks.

The 0-6-km bulk shear (Fig. 14) of both TO composite simulations provided is considerably stronger [up to $20 \mathrm{kt}\left(\sim 10.3 \mathrm{~m} \mathrm{~s}^{-1}\right)$ ] than NTO2, but the magnitudes are similar to those seen in NTO4 (particularly in 
$\mathrm{mb}$
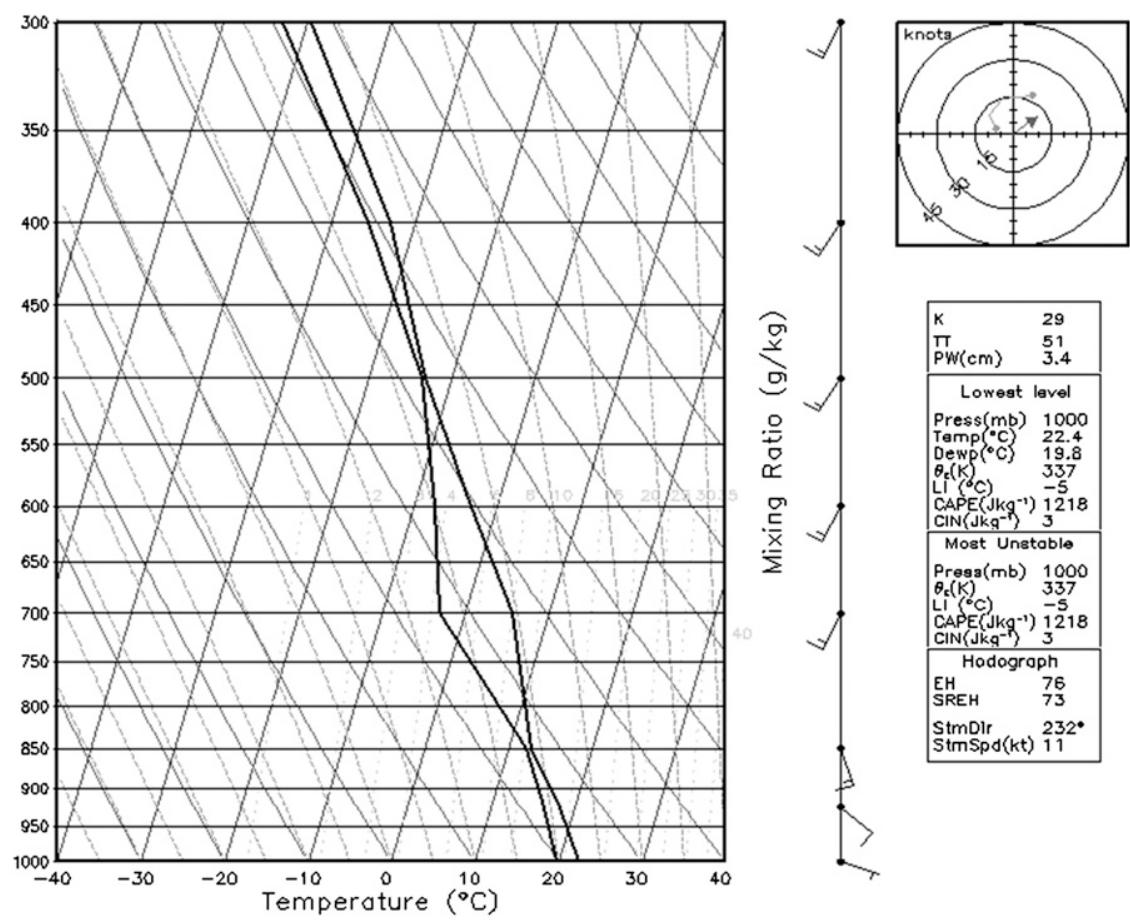

FIG. 12. Skew $T-\log p$ valid at the time of the TO at 0000 UTC 27 May 1973.
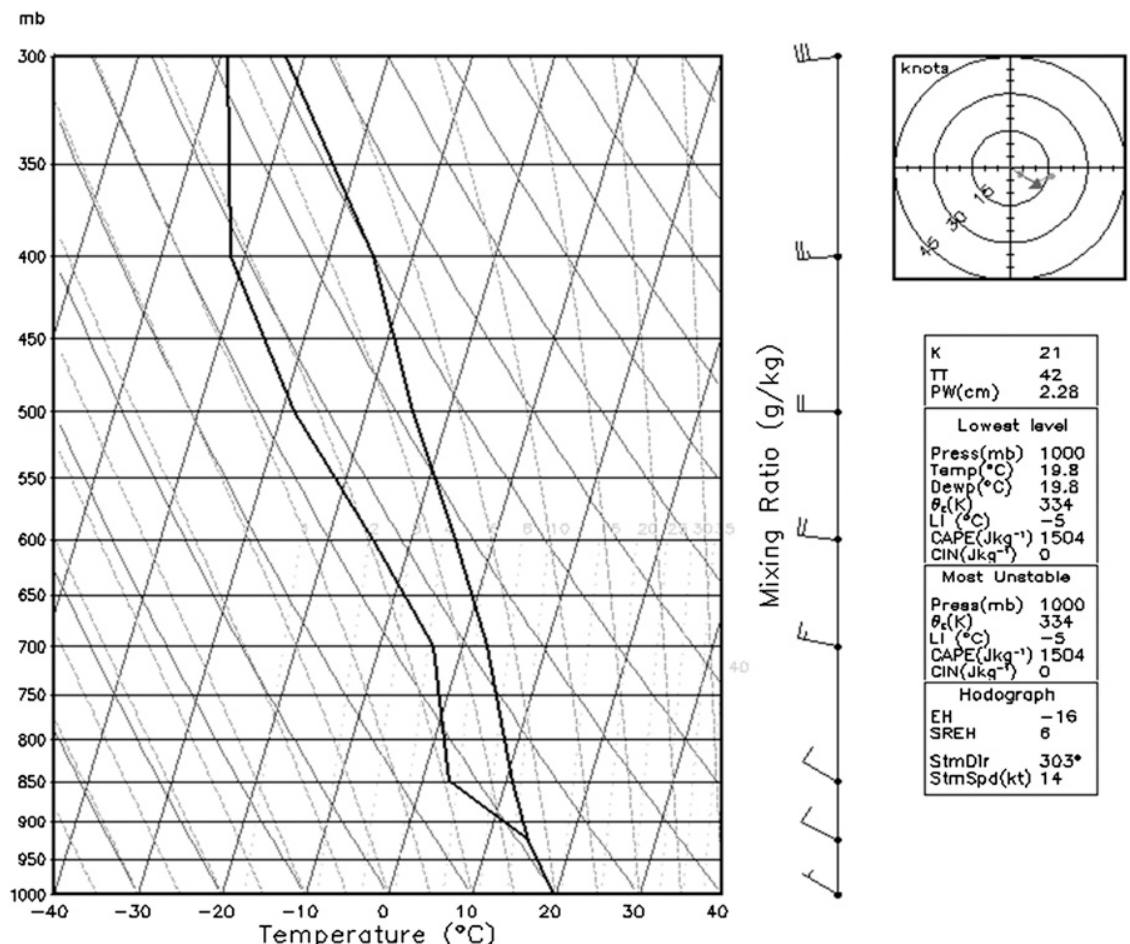

FIG. 13. Skew $T-\log p$ valid at the time of the NTO at 0000 UTC 29 Apr 1981. 


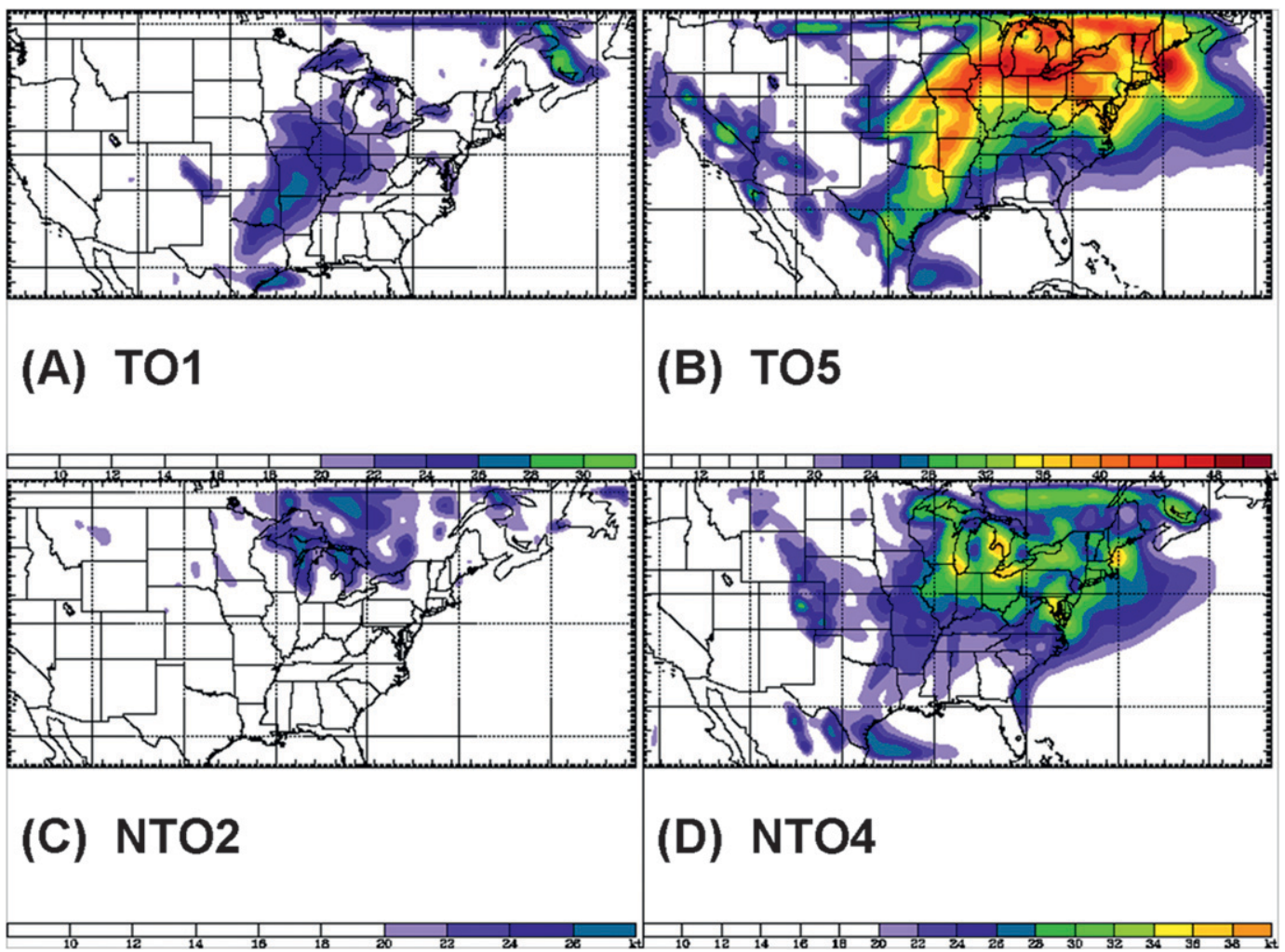

FIG. 14. Composite 0-6-km bulk shear for a 24-h WRF simulation of (a) TO1, (b) TO5, (c) NTO2, and (d) NTO4.

TO1). The areal coverage of the $30-\mathrm{kt}\left(\sim 15.4 \mathrm{~m} \mathrm{~s}^{-1}\right)$ 0-6-km bulk shear contour is larger in NTO4 than TO1, but is considerably smaller than that of TO5. Thus, the WRF is indicating significant bulk shear availability for tornado production in TO5, but is incapable of isolating significant differences in bulk shear availability between NTO4 and TO1, a surprising result given the large differences in the composite fields. The 0-1-km SREH fields (Fig. 15) reveal more significant differences between the outbreak types, as 0-1-km SREH magnitudes in TO1 and TO5 are up to $100 \mathrm{~m}^{2} \mathrm{~s}^{-2}$ larger than NTO4, and SREH is less than $100 \mathrm{~m}^{2} \mathrm{~s}^{-2}$ throughout the entire domain of NTO2. The M09 algorithm consistently suggested that SREH was a better discriminator than bulk shear, a result supported here and in the composite soundings for TO1 and NTO4 (Figs. 9 and 10). Thus, TOs and NTOs are being properly depicted by the WRF simulations.

\section{2) DISCRIMINATION OF THE COMPOSITES WITH THE M09 ALGORITHM}

To test an objective forecast application of the composite simulations, a SVM formulated following the methodology of M09 is trained on the relevant covariates from the composite WRF simulations at 24-, 48-, and 72-h lead time. The SVM then was tested on the original 100 outbreak events to determine the ability of the composites to discriminate outbreak type. Results from this analysis are in Table 3.

At $24 \mathrm{~h}$, probability of detection (POD) values near 1 are observed, in combination with false-alarm rate (FAR) and probability of false detection (POFD) values of 0.3 and 0.4 , respectively. The bias value of 1.34 suggests the SVM is overpredicting TOs, a result supported by the high POD and FAR values. However, the Heidke skill score (HSS) of 0.53 is indicative of useful skill in outbreak discrimination of the SVM algorithm. At $48 \mathrm{~h}$, POD increases at the expense of the model further overpredicting TOs (bias of 1.54) and thus a higher FAR and POFD. The higher FAR and POFD result in a consid-

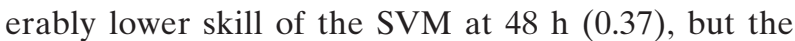
algorithm still has some success in outbreak discrimination. At $72 \mathrm{~h}$, the algorithm does not overpredict TOs (bias of 1.08), but the POD drops as a result of fewer TO classifications. However, the FAR and POFD decrease only slightly from $48 \mathrm{~h}$ and the HSS remains essentially unchanged at this lead time. It is evident that the composites begin to lose discrimination capability after 24-h lead time, but retain marginal discrimination skill (HSS $\sim 0.3$ ) even out to 72 -h lead time. 


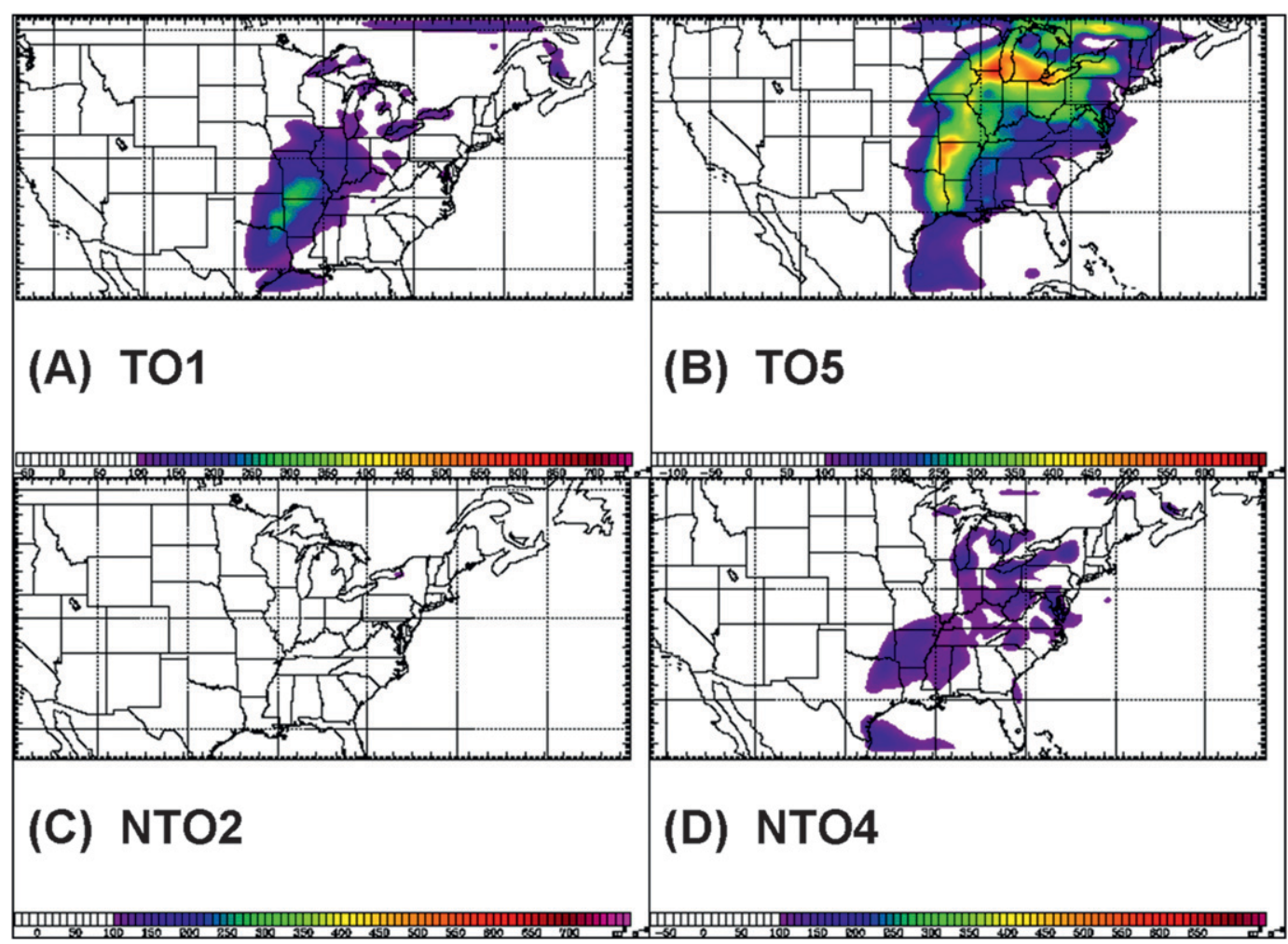

FIG. 15. As in Fig. 14, but for 0-1-km SREH.

\section{Summary and conclusions}

The primary goal of this work was to determine the synoptic-scale characteristics of TOs and NTOs in an effort to distinguish between the two. This was accomplished through outbreak relative synoptic-scale pattern composites of TOs and NTOs. Six composite map types of TOs and NTOs were derived from clusters of RPC loadings. The resulting composites were simulated with the WRF at 24-, 48-, and 72-h lead time, and a SVM trained on the WRF composite simulations was used to determine the forecast ability of the composites.

The TO composites revealed features quite different from the NTO composites. Synoptic-scale TO fields were characterized by a strong $500-\mathrm{mb}$ trough and associated vorticity maximum that was larger in magnitude than the 500-mb NTO fields. Additionally, TO $850-\mathrm{mb}$ composite height troughs exhibited positive, negative, and neutral tilt (and associated stronger SREH), and had stronger thermal advection than the NTO composite maps. Vertical soundings at the composite outbreak centroids revealed larger helicity and bulk shear values in the TO environments, ingredients deemed important for TOs by M09 and S09. CAPE values were zero in these soundings because of the compositing methodology employed, but the impact of buoyant instability on outbreak discrimination is minimal (M09 and S09).
The WRF simulations of the TO and NTO storm types generally revealed greater $0-6-\mathrm{km}$ bulk shear magnitudes and $0-1-\mathrm{km}$ SREH magnitudes in proximity of the TO centroid, relative to the NTO center. However, NTO4 and TO1 had bulk shear patterns that could be identified as either an NTO or a TO. These similarities did not appear in the $0-1-\mathrm{km}$ SREH fields, as the TOs had consistently higher SREH values than NTOs. The SVM algorithm trained on the composites exhibited high POD and HSS values at 24 and $48 \mathrm{~h}$ (Table 3), but suffered from relatively high FAR and POFD due to overprediction of TOs by the SVM. At $72 \mathrm{~h}$, this overprediction ceased, but the POD decreased as a result while maintaining marginal FAR and POFD values. It was noted that the skill of the SVM dropped

TABLE 3. Contingency statistics of the SVM classifications for each composite at 24-, 48-, and 72-h lead time based on 99 total independent classifications of each outbreak type.

\begin{tabular}{lccc}
\hline \hline Statistic & $24 \mathrm{~h}$ & $48 \mathrm{~h}$ & $72 \mathrm{~h}$ \\
\hline PC & 0.768 & 0.687 & 0.677 \\
POD & 0.940 & 0.960 & 0.720 \\
FAR & 0.299 & 0.377 & 0.333 \\
POFD & 0.408 & 0.592 & 0.367 \\
BIAS & 1.340 & 1.540 & 1.080 \\
HSS & 0.534 & 0.370 & 0.353 \\
\hline
\end{tabular}


significantly between 24 and 48 h, but remained relatively constant between 48 and $72 \mathrm{~h}$, suggesting that synoptic patterns are less distinguishable with increasing lead time, as expected.

The results of this study reveal the importance of SREH and shear, particularly directional shear (veering wind profiles), in the development of a TO environment. Most NTO composites had marginal shear and SREH magnitudes relative to the TO composites both in the original composite fields and in the WRF simulations of the composites. The study revealed a classical synopticscale pattern for a typical major TO with minor deviations (e.g., the tilt of the trough at $850 \mathrm{mb}$ ), but several types of NTOs resulted from the analysis, likely attributable to the known seasonality of NTOs (Shafer et al. 2010). Overall, the results demonstrate clear synopticscale differences between the two outbreak types, and the WRF simulations support that conclusion.

The methods employed in this study will be used for future composite research with severe weather outbreaks. The techniques used herein can be applied to a variety of severe weather topics, as it is not limited to outbreaks. More cases should improve the robustness of the composites, possibly resulting in more map types. However, given the relative rarity of major TOs, it might take decades to provide an adequate sample (Doswell 2007). The synoptic-scale patterns were integrated as WRF input data easily, so incorporation of the composites into a data assimilation scheme for an operational numerical weather prediction model would likely improve that model's ability to predict imminent severe weather outbreak type. Operational forecasting applications of this work have yet to be fully developed, but are being considered for future investigation.

Acknowledgments. We wish to thank the Oklahoma Supercomputing Center for Education and Research (OSCER) for use of their computing facilities. Specifically, we wish to thank Dr. Henry Neeman for his assistance in creation of the synoptic-scale composites on the OSCER supercomputing clusters. We would also like to thank the reviewers who suggested another source of possible SREH reduction in our composites. We wish to thank the National Center for Atmospheric Research for access to the NCEP-NCAR reanalysis data. We thank Dr. Peter Lamb for his support of the project as well. This work was funded by NSF Grants ATM0527934 and AGS-0831359.

\section{REFERENCES}

Agee, E., C. Church, C. Morris, and J. Snow, 1975: Some synoptic aspects and dynamic features of vortices associated with the tornado outbreak of 3 April 1974. Mon. Wea. Rev., 103, 318-333.

Banacos, P. C., and M. L. Ekster, 2010: The association of the elevated mixed layer with significant severe weather events in the northeastern United States. Wea. Forecasting, 25, 1082-1102.

Barnes, S. L., 1964: A technique for maximizing details in numerical weather map analysis. J. Appl. Meteor., 3, 396-409.

Beebe, R. G., 1956: Tornado composite charts. Mon. Wea. Rev., 84, 127-142.

Bell Laboratories, 2011: R version 2.13.0. Mississippi State University.

Burke, P., and D. Schultz, 2004: A 4-year climatology of cold season bow echoes over the continental United States. Wea. Forecasting, 19, 1061-1074.

Carr, J. A., 1952: A preliminary report on the tornadoes of March 21-22, 1952. Mon. Wea. Rev., 80, 50-58.

Coniglio, M., D. Stensrud, and M. Richman, 2004: An observational study of derecho-producing convective systems. Wea. Forecasting, 19, 320-337.

Corfidi, S., S. Weiss, J. Kain, S. Corfidi, R. Rabin, and J. Levit, 2010: Revisiting the 3-4 April 1974 Super Outbreak of tornadoes. Wea. Forecasting, 25, 465-510.

Cristianini, N., and J. Shawe-Taylor, 2000: Support Vector Machines and Other Kernel-Based Learning Methods. Cambridge University Press, 189 pp.

Doswell, C. A., III, 2007: Small sample size and data quality issues illustrated using tornado occurrence data. Electron. J. Severe Storms Meteor., 2 (5), 1-16.

, S. J. Weiss, and R. H. Johns, 1993: Tornado forecasting: A review. The Tornado: Its Structure, Dynamics, Prediction, and Hazards, Geophys. Monogr., Vol. 79, Amer. Geophys. Union, 557-571.

— R. Edwards, R. L. Thompson, J. A. Hart, and K. C. Crosbie, 2006: A simple and flexible method for ranking severe weather events. Wea. Forecasting, 21, 939-951.

Ferguson, E. W., F. Ostby, and P. Leftwich, 1987: The tornado season of 1985. Mon. Wea. Rev., 115, 1437-1445.

Fujita, T., D. L. Bradbury, and C. F. Van Thullenar, 1970: Palm Sunday tornadoes of April 11, 1965. Mon. Wea. Rev., 98, 29-69.

Gaffin, D. M., and S. S. Parker, 2006: A climatology of synoptic conditions associated with significant tornadoes over the southern Appalachian region. Wea. Forecasting, 21, 735-751.

Galway, J. G., 1975: Relationship of tornado deaths to severe weather watch areas. Mon. Wea. Rev., 103, 737-741.

_ 1977: Some climatological aspects of tornado outbreaks. Mon. Wea. Rev., 105, 477-484.

Glickman, T., Ed., 2000: Glossary of Meteorology. 2nd ed. Amer. Meteor. Soc., 855 pp.

Grazulis, T. P., 1993: Significant Tornadoes 1680-1991: A Chronology and Analysis of Events. Environmental Films, 1340 pp.

Hagemeyer, B., 1997: Peninsular Florida tornado outbreaks. Wea. Forecasting, 12, 399-427.

Hsu, C. P., and J. M. Wallace, 1976: The global distribution of annual and semiannual cycles in sea level pressure. Mon. Wea. Rev., 104, 1597-1601.

Johns, R., 1984: A synoptic climatology of northwest-flow severe weather outbreaks. Part II: Meteorological parameters and synoptic patterns. Mon. Wea. Rev., 112, 449-464.

- 1993: Meteorological conditions associated with bow echo development in convective storms. Wea. Forecasting, 8, 294-299. 
, and W. Hirt, 1987: Derechos: Widespread convectively induced windstorms. Wea. Forecasting, 2, 32-49.

Jones, T. A., K. M. McGrath, and J. T. Snow, 2004: Association between NSSL mesocyclone detection algorithm-detected vortices and tornadoes. Wea. Forecasting, 19, 872-890.

Kalnay, E., and Coauthors, 1996: The NCEP/NCAR 40-Year Reanalysis Project. Bull. Amer. Meteor. Soc., 77, 437-471.

Lanicci, J. M., and T. T. Warner, 1991: A synoptic climatology of the elevated mixed-layer inversion over the southern Great Plains in spring. Part III: Relationship to severe-storms climatology. Wea. Forecasting, 6, 214-226.

Lee, B. D., B. F. Jewett, and R. B. Wilhelmson, 2006: The 19 April 1996 Illinois Tornado outbreak. Part II: Cell mergers and associated tornado incidence. Wea. Forecasting, 21, 449-464.

Lowe, A. B., and G. A. McKay, 1962: Tornado composite charts for the Canadian Prairies. J. Appl. Meteor., 1, 157-162.

Mercer, A. E., C. M. Shafer, C. A. Doswell, L. M. Leslie, and M. B. Richman, 2009: Objective classification of tornadic and nontornadic severe weather outbreaks. Mon. Wea. Rev., 137, 4355-4368.

Metz, N., and L. Bosart, 2010: Derecho and MCS development, evolution, and multiscale interactions during 3-5 July 2003. Mon. Wea. Rev., 138, 3048-3070.

Miller, R., 1972: Notes on analysis and severe-storm forecasting procedures of the Air Force Global Weather Center. Air Weather Service Tech. Rep. 200, rev. ed. Air Weather Service, Scott Air Force Base, IL, 184 pp.

Mook, C. P., 1954: A preferred thickness line accompanying multiple tornado occurrences. Mon. Wea. Rev., 82, 160-162.

North, G. R., T. L. Bell, R. F. Calahan, and F. J. Moeng, 1982: Sampling errors in the estimation of empirical orthogonal functions. Mon. Wea. Rev., 110, 699-706.

Pautz, M. E., 1969: Severe local storm occurrences, 1955-1967. ESSA Tech. Memo. WBTM FCST12, Washington, DC, 3-4.

Richman, M. B., 1986: Rotation of principal components. J. Climatol., 6, 293-335.

, and A. E. Mercer, 2012: Identification of intraseasonal modes of variability using rotated principal components. Atmospheric Model Applications, I. Yucel, Ed., Intech, 273-296.
Roebber, P., D. Schultz, and R. Romero, 2002: Synoptic regulation of the 3 May 1999 tornado outbreak. Wea. Forecasting, 17, 399-429.

Rousseeuw, P. J., 1987: Silhouettes: A graphical aid to the interpretation and validation for cluster analysis. J. Comput. Appl. Math., 20, 53-65.

Schaefer, J., and C. A. Doswell III, 1984: Empirical orthogonal function expansion applied to progressive tornado outbreaks. J. Meteor. Soc. Japan, 62, 929-936.

— , and R. Edwards, 1999: The SPC tornado/severe thunderstorm database. Preprints, 11th Conf. on Applied Climatology, Dallas, TX, Amer. Meteor. Soc., 603-606.

Schneider, R. S., J. T. Schaefer, and H. E. Brooks, 2004: Tornado outbreak days: An updated and expanded climatology (18752003). Preprints, 22nd Conf. on Severe Local Storms, Hyannis, MA, Amer. Meteor. Soc., P5.1.[Available online at http://ams. confex.com/ams/11aram22sls/techprogram/paper_82031.htm.]

Shafer, C. M., A. E. Mercer, C. A. Doswell, M. B. Richman, and L. M. Leslie, 2009: Evaluation of WRF forecasts of tornadic and nontornadic outbreaks when initialized with synopticscale input. Mon. Wea. Rev., 137, 1250-1271.

,$- \ldots$, L. M. Leslie, M. B. Richman, and C. A. Doswell, 2010: Evaluation of WRF model simulations of tornadic and nontornadic outbreaks that occur in the spring and fall. Mon. Wea. Rev., 138, 4098-4119.

Skamarock, W. C., and Coauthors, 2008: A description of the Advanced Research WRF version 3. NCAR Tech. Note NCAR/TN-475+STR, 125 pp. [Available online at http:// www.mmm.ucar.edu/wrf/users/docs/arw_v3.pdf.]

Swinbank, R., and R. J. Purser, 2006: Fibonacci grids: A novel approach to global modeling. Quart. J. Roy. Meteor. Soc., 132, 1769-1793.

Wasula, A. C., L. F. Bosart, R. Schneider, S. J. Weiss, R. H. Johns, G. S. Manikin, and P. Welsh, 2007: Mesoscale aspects of the rapid intensification of a tornadic convective line across central Florida: 22-23 February 1998. Wea. Forecasting, 22, 223-243.

Whiting, R. M., and R. E. Bailey, 1957: Some meteorological relationships in the prediction of tornadoes. Mon. Wea. Rev., 85, 141-150.

Wilks, D. S., 2006: Statistical Methods in the Atmospheric Sciences. Academic Press, 627 pp. 
Copyright of Monthly Weather Review is the property of American Meteorological Society and its content may not be copied or emailed to multiple sites or posted to a listserv without the copyright holder's express written permission. However, users may print, download, or email articles for individual use. 